\title{
Symmetry and Middle Paleolithic Points: A Case Study of Iran's Middle Paleolithic Points
}

\section{Nasim Feizi}

Tarbiat Modares University

Hamed Vahdati Nasab ( $\sim$ hamedvahdati@yahoo.com )

Tarbiat Modares University

\section{Research Article}

Keywords: Middle Paleolithic, Projectile Point, Throwing, Symmetry, Drag

Posted Date: September 14th, 2021

DOI: https://doi.org/10.21203/rs.3.rs-257471/v2

License: (c) (i) This work is licensed under a Creative Commons Attribution 4.0 International License. Read Full License 

Points Iran. **Associate Professor, Department of Archaeology, Tarbiat Modares University, Tehran, Iran, Correspondent author

\section{Abstract}

10 The throwing capacity of Middle

11 Paleolithic points has been an important

12 issue since the discovery of the

13 Neanderthal's toolbox. In the Middle

14 Paleolithic, Homos (Neanderthals or $H$.

15 sapiens) made thrusting points with limited or no throwing capability. Projectile points as a long-range weapon were replaced with the trusting and guaranteed the survival of modern humans. Several attempts have been made to recognize the aerodynamic differences between Middle and Upper Paleolithic Points. However, up to now, far too little attention has been paid to the symmetry and projectile motion rules related to it. In this paper, symmetry and other morphological features, including

\section{Introduction}

"Competition hypothesis" as an essential theory highlights the role of the aerodynamic ability of modern human's projectile points to overcome and finally extinct the Neanderthals (Shea, 2003). Shea did not have evidence to support the extensive use of stone-tipped projectiles in Africa, the Levant, or Europe until $40 \mathrm{Ka}$ (Shea, 2006). In the following researches, Churchill and Rhodes (2009) do subscribe to this view. They show evidence of diversity in Scapular and ulnar morphology within and between groups of Fossil humans and modern humans that attributes
27 length, width, weight, cross-sectional area, 28 flatting, and elongation, have been 29 measured on 280 points collected from five 30 Iranian Middle Paleolithic sites. In addition, 31 the Iranian Middle Paleolithic data is 32 compared with several Middle, Upper, and 33 Neolithic sites outside of Iran. The results 34 indicate that the evolution of symmetry 35 alongside increased elongation, and 36 proportionality in measurable 37 characteristics was a critical factor in 38 creating projectile points.

39 Keywords: Middle Paleolithic, Projectile 40 Point, Throwing, Symmetry, Drag

57 the origin of the projectile point to modern 58 man from Africa and at the same time as his 59 presence in Europe is scattered in the land 60 of Neanderthals (Churchill and Rhodes, 61 2009). However, Villa and Soriano could 62 not accept this theory based on evidence 63 from Ethiopia and Botswana. Nevertheless, 64 Delpiane and his colleagues (2019) 65 believed that late Neanderthals innovated 66 projectile by backed artifacts that were 67 hafted in different regions of Europe 68 independently based on the large 69 assemblage of data from unit A9 at Fumane 70 Cave (Delpiane et al., 2019). On the other 71 hand, Sano and his colleagues (2019) 
provided contradictory evidence in southern Italy. According to microscopic analysis of backed lithic pieces from the Uluzzian site, they show that this projectile technology was conveyed to Europe from Africa at around $45 \mathrm{ka}$ by modern humans (Sano et al., 2019). As it turns out, the issue is quite challenging. However, the general opinion is that Neanderthals could not make projectile points, although the later experimental and archeological evidence in Abri du Maras, France, and the Northern Iberian Peninsula rejects this view (Hardy et al., 2013; Rios-Garaizar, 2016). Therefore, one should look for a way to measure the throwing capacity of the lithic points specific to these two human groups separately. Accordingly, several experimental trials have been performed to investigate the throwing capacity of Middle Paleolithic projectile points (e.g., Shea et al. 2001; Shea et al., 2002; Sisk and Shea, 2009; Newman and Moore, 2013; RiosGaraizar, 2016; Clarkson, 2016).

Most researchers generally focused on measuring the cross-section area and perimeter to determine the aerodynamic features of points and throwing power, especially in the Middle Paleolithic (Hughes, 1998; Shea, 2006; Shea and Sisk, 2011; Hardy et al., 2013; Wilkins et al., 2012 \& 2014, Rios-Garaizar, 2016; Clarkson, 2016, Schoville et al., 2016; Mika, 2020; Sitton et al., 2020; Mullen et al., 2021). Although there has been much debate about the validity of the morphological impact of these factors on throwing capacity (For example, Clarkson (2016)), recent experimental researches seem to support their credibility (Schoville et al., 2016; Mika, 2020; Sitton et al., 2020; Mullen et al., 2021). So far, very little attention has been paid to the role of
116 symmetry in Paleolithic projectile's 117 functions. Accordingly, this research aims 118 to explore the relationship between 119 symmetry and other morphological features 120 in throwing capacity.

\section{2. Archaeological background: The 122 Iranian Middle Paleolithic sites}

123 Iran with an area of 1.648.000 square 124 kilometers is located in southwest Asia and 125 surrounded by the Caspian Sea at north and 126 the Persian Gulf and Oman Sea at south 127 (Fig. 1). This area is rich in biological and 128 geographical diversities; moreover, Iran is 129 even more significant because of the 130 presence of hominid remains in its 131 neighboring regions (e.g., Shanidar in Iraqi 132 Zagros, Dmanisi in northwest of Iran in 133 Republic of Georgia and Teshik-Tash in 134 Uzbekistan in north east of Iranian plateau). 135 In addition to that, cultural remains of 136 Paleolithic groups in the shape of lithic 137 materials assigned to all Paleolithic 138 subdivisions have been recorded in Iran in 139 large numbers (Vahdati Nasab, 2010). 140 During the last decade numerous 141 Paleolithic field missions had led to the 142 discovery of a handful of Paleolithic sites 143 across the Iranian plateau among which are 144 several Middle Paleolithic open sites that 145 the points collected through systematic 146 surface surveys of five of those are subject 147 to this research (Fig. 1): Mirak, Chah-e 148 Jam, The Mehran plain, Kuhrang, and 149 Bandepey. These sites are located in very 150 different landscapes across Iran. For 151 instance, Mirak and Chah-e Jam are 152 situated at the northern edge of the Iranian 153 Central Desert in very dry and arid regions 154 (Vahdati Nasab, et al., 2013; Vahdati Nasab 155 and Hashemi, 2016). On the other hand, 
Bandepey is a huge lithic scatter located at the southern coast of the Caspian Sea in a Mediterranean forest (Vahdati Nasab, et al., 2015). Mehran Plain and Kuhrang are both located at the Zagros Mountains; however,
161 while Kuhrang is a high elevated site (2000 $162 \mathrm{~m}$ above sea level), Mehran Plain is situated 163 on the lowland plains of southern Zagros 164 (Roustaei, 2010; Javanmardzadeh, 2016 ).
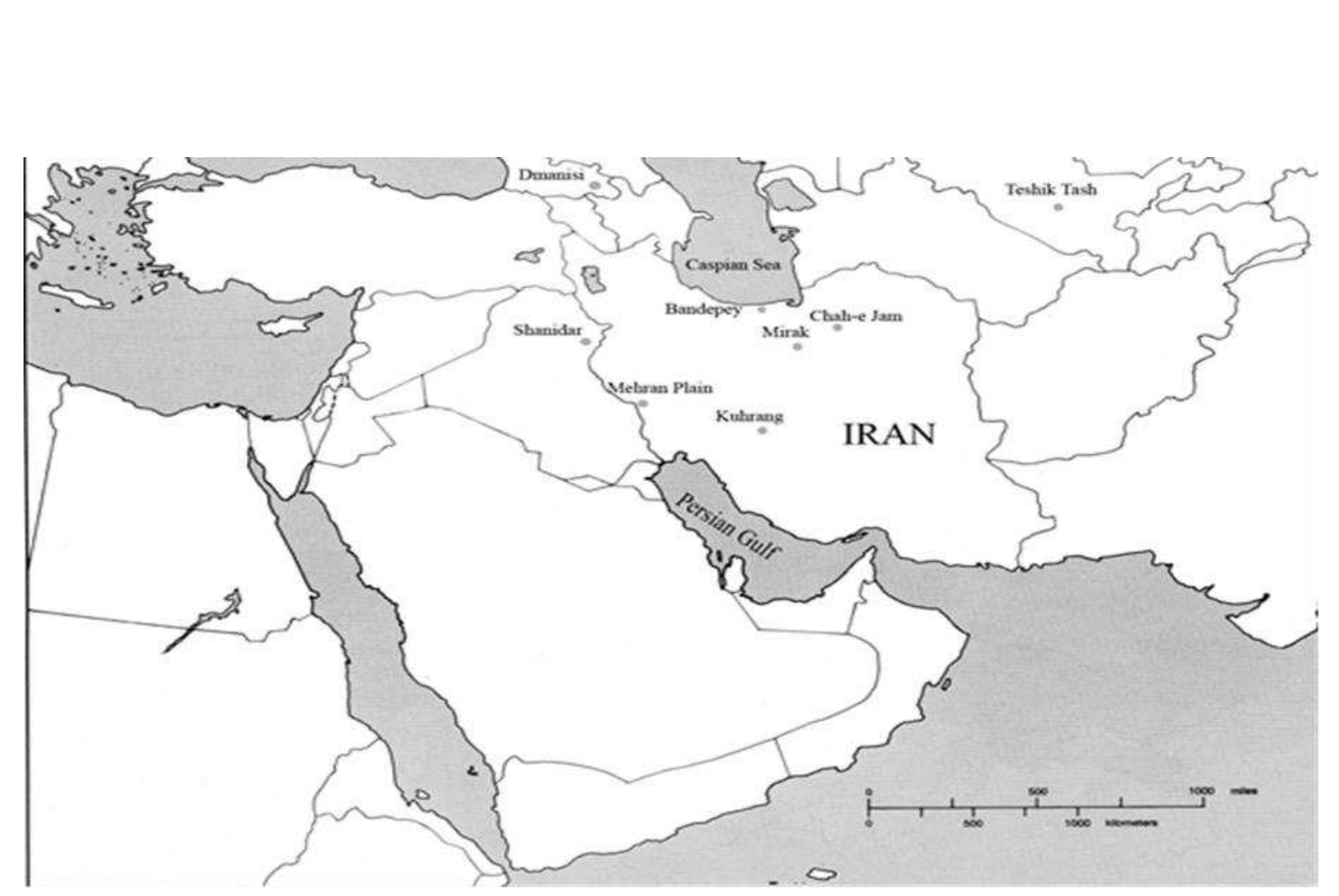

Figure 1. The location of Middle Paleolithic sites on the Iranian Plateau

\section{Methodological background: Projectile Physics Perspective}

In 1998, Hughes examined the engineering of primitive weaponry (mass, crosssectional area, perimeter, and the shape and durability variables from tips from Mummy Cave in detail. Accordingly, from an evolutionary point of view, it is divided into four groups, including the thrusting spear, throwing spear, spearthrower, and bow (Hughes, 1998).

In projectiles, what is interesting is that the experimental research revealed that there is a direct relationship between the existence of the tip and its penetrating power (Wilkins et al, $2014 \& 2012$ ). In addition, there is an inverse relationship between the size of 87 triangular stone arrow tips and the amount
188 of penetration (Mika et al., 2020). For 189 example, we can see such a relationship in 190 the projectile point of the Uluzzian site 191 (around45 ka) in southern Italy (Sano et al., 192 2019), the arrow and arrowheads of Eastern 193 North America in the late first millennium 194 AD (Mika et al., 2020), and the Neo195 Assyrian bronze arrowhead in the site of 196 Ziyaret Tepe, located in southeastern 197 Turkey (Mullen et al., 2021).

198 However, John Shea emphasizes that in 199 the Levant, Africa, and Europe, the cross200 section of the Middle Paleolithic points is 201 large. Thus, these points are not useful tools 202 for penetrating into a target's body. 203 Therefore, the lithic points were not able to 204 throw until some 40000 years ago (Shea, 
215 Garaizar, 2016).

216 Therefore, it is important to consider the

217 situation from the point of view of physics.

218 Based on the penetration equation,

219 Prehistoric Projectile penetration is affected

220 by four variables: mass $(\mathrm{M})$, velocity $\left(V_{0}\right)$,

221 tip cross-sectional area (A), and projectile

222 shape (C), and drag force predict the most

223 optimal shape for penetration (Hughes,

224 1998).

$$
\text { Penetration }=\frac{M V_{0}}{C A}
$$

(Sperrazza and Kokinakis, 1968, p. 163)

229 The following formula (3) also determines 230 the drag force or the friction force.

$$
\mathrm{D}=\frac{1}{2} \rho \mathrm{V}_{t}^{2} \mathrm{~A} . \mathrm{C} .
$$

236 These formulas show a direct relationship

237 between the increasing coefficient of the 238 drag and reducing speed, between the drag 239 and cross-section areas. The drag force 240 formula shows that the smaller the cross241 sectional area, the lower the drag force 242 acting upon the projectile. Accordingly,
243 from the drag reduction point of view, the 244 cross-section area can be a useful factor. 245 Furthermore, in the throwing motion, the 246 shape of the trajectory and its range is 247 affected by the drag (Ang, 2013). 248 Accordingly, it seems that the cross-section 249 area affected the drag amount although its 250 effect depends on other factors. For 251 example, the joint between the point and the 252 shaft is a key criterion in the performance 253 of the spear (Pétillon et al., 2011).

254 On another hand, given the Mechanics of 255 fluids, it is evident that what is essential for 256 effective throwing is a projectile's shape 257 and fluid pressure force that acts upon its 258 form. Interestingly, Theodore von Kármán 259 focused upon the impact of these 260 components in organisms moving, such as 261 Trout swimming. He compared the dorsal 262 and ventral parts of the trout body with a 263 modern airfoil; therefore, his research was 264 one of the first studies to draw attention to 265 trout fish swimming behavior and 266 overcome the drag. He stresses that there is 267 a relationship between body shape and 268 reducing drag in organism life (Von 269 Kármán, 1963: 7-8). This result raises a 270 pertinent question. What kind of body 271 shape causes to decline sharply in the drag? 272 To put it another way, what impact does the 273 projectile shape have on its aerodynamic?

274 For Vogel, the characters that we can see in 275 the body forms of the tuna, mackerel, or the 276 design of modern airfoils, including slender 277 shapes, blunt noses, and sharp trailing are 278 what caused to minimize the drag. (Vogel, 279 1994: 147-8). We know that the fish body 280 with such characters has a symmetrical 281 shape. Generally, the fluid pressure that 282 acts on the projectile depends on its shape. 283 This vital principle was obtained based on 284 studies from the macroscopic to the 285 microscopic scale. For example, fish 
286 swimming at the macroscopic level and 287 fungal spores at the macroscopic level are 288 examples that are well-studied (Vogel, 289 2005). In addition to biological samples, the 290 navigation industry emphasizes physical 291 features (Roper, 2008). It is worth 292 mentioning that drag minimization is the 293 only way to an accurate and useful throw. 294 However, how can we minimize the drag 295 force on something moving through the air? 296 Applied science research answered this 297 question using the laws of physics.

298 The fact that the drag forces are directly 299 proportional with the coefficient of 300 viscosity (Wilson, 2000: 322). Viscosity is 301 a parameter that indicates the degree of 302 resistance to the flow of the fluid, and liquid 303 viscosity is more than gas viscosity. This 304 parameter is a determining factor in the 305 flow pattern (Adams et al., 1960: 332). So 306 that, viscosity is inversely related to inertia, 307 and the relative of these two parameters is 308 called the Reynolds number. It is necessary 309 to mention that when the viscosity is zero, 310 the fluid will continue to flow indefinitely 311 because the resistance to flow is zero. Of 312 course, such an absolute zero does not 313 happen in the real world. In contrast, 314 viscous effects are dominant in low 315 Reynolds number flows; therefore, the flow 316 is slow and layered (Oteh, 2008: 311). 317 Interestingly, the minimal drag shape has 318 been defended for slowly creeping flows in 319 Reynolds (Re) equals zero (Pironneau, 3201973 \& Bourot, 1974). Accordingly, Roper 321 and his colleagues have proven that the 322 shape of the body that minimizes the drag 323 force is highly symmetrical at moderate 324 Reynolds. They show that although the 325 perfect projectile is weakly asymmetric, the 326 projectiles preserve quite fore-aft 327 symmetry. However, the flow around such 328 bodies becomes markedly asymmetric 329 (Roper et al., 2008). On the other hand, 330 during an experimentally conducted 331 research, it is shown that rounded and sharp noses in a symmetrical projectile have a better performance than flat noses and spherical ones. Nevertheless, the round nose projectile has the best performance in long distances, while the sharp nose has a close performance with a round nose, it is more suitable for hunting due to its greater penetration (Salimipour et al., 2018). Thus, it should be noted that the shape and size of a projectile are effective in determining drag (Ang, 2013). Accordingly, it seems possible that in different fluids, both in ultrasound and in ultrasound, the degree of symmetry has a significant effect on successful throwing. Perhaps it can explain why most of the Upper Paleolithic points are throwing-capable. Moreover, an accurate projectile may be considered as a consequence of changing morphological features with the evolution of the symmetry.

\section{Materials and Methods}

There are different ways to measure symmetry in two-dimensional space. However, 3D methods have recently demonstrated that the third dimension and the degree proportion of preparation removals are critical for increasing symmetry (Feizi et al., 2018). For example, based on previous researches on the points of the mentioned site, it was proved that the deviation of symmetry in most Middle Paleolithic points has a similar pattern (Feizi et al., 2019). We think that the results are likely to be related to the interaction between the proportion of preparation removals and symmetry and the effect of these interactions on morphology (Feizi et al., 2018; Feizi et al., 2019). Thus, we calculated the deviation from the symmetry of 5 Iranian areas with the threedimensional method. But for comparing our 
375 data with other sites, we used a 376 straightforward method called the 377 quadrangle technique.

378 In summary, in our 3D method, we prepare 379 two three-dimensional models from each 380 point. One of them is a computable surface 381 to measure the symmetry of a point. This 382 surface is called the Mesh (or Test) model. 383 We will have meshed all surface points 384 using Geomagic software ${ }^{1}$ (version 2013). By 385 this, the software will have passed a triangle 386 from any three points that are not on a 387 straight line. This operation leads to doing 388 math calculations on a triangulated surface.

389 For example, if we want to calculate a point 390 area, the software quickly collects the 391 triangle areas that covered all Surface 392 points and calculates the total area of that 393 point. In addition to the countable surface, 394 we make a Reference Model (CAD) to 395 calculate the deviation of each point from 396 the symmetry mode. The CAD is an 397 incomputable surface in which all 398 topographic characteristics are determined 399 precisely and only used for comparison. 400 Then the two levels are aligned. So that, the 401 left side of the point set on the right side, 402 just like a veneer. With this logic, the more 403 symmetrical the two sides of the point are, 404 the more accurately the surfaces are placed 405 on top of each other. In this position, the 406 upper surface acts as a suitable veneer. This 407 alignment is done with a particular 408 technique and the most accurate software. 409 The software is comparing the symmetry of 410 the point concerning all the topographical 411 features of the two sides. At the final step, 412 the degree of deviation from symmetry is 413 defined as a series of numbers, and then the 414 obtained data are analyzed by SPSS 23 415 (Feizi et al., 2018).

${ }^{1}$ Geomagic $^{\circledR}$, Morrisville, North Carolina
In the paper, any lithic point or any other 417 2D or 3D dimensional shape is inscribed in 418 a quadrangle so that four (or three) vertices 419 of the lithic point are tangent to the four 420 sides of the quadrangle. Next, MB-ruler ${ }^{2}$ is 421 used to cut the quadrilateral from its center. 422 It is worth noting that this ruler was 423 designed by Markus Bader. The ruler is a 424 high-flexibility ruler that measures 425 distances and angles from a computer 426 screen as well as distances from maps and 427 aerial photographs. Thus, without paying 428 attention to the point, the quadrangle is 429 halved. It means that if a point is 430 symmetrical, it will be half from its 431 symmetrical axis with the quadrangle. 432 Accordingly, as shown in Figure 2, the 433 quadrangle is halved, and each triangular 434 lithic point is divided into two smaller 435 triangles (the right and left), and the areas 436 of the two triangles are calculated (Fig. 2). 437 If the left and right are equal, then the 438 difference between the two sides of the 439 lithic point will be equal to zero. Hence, the 440 symmetry is perfect. However, perfect 441 symmetry is impossible in reality, and there 442 is always a numeric value $(\mathrm{SL}-\mathrm{SR} /=0)$. 443 This numeric value is the deviation of ideal 444 symmetry (D.S.) (3), and I.D.S. (4) is equal 445 to D.S divided by the total area of a lithic 446 point (S.T.) (Feizi et al., 2018).

447

$$
\begin{array}{r}
\text { D.S }=\left|S_{L}-S_{R}\right| \\
\text { I.D.S }=\frac{\left|S_{L}-S_{R}\right|}{S_{T}}
\end{array}
$$

449 Accordingly, we compared the deviation 450 of symmetry of lithic points in the Middle 451 and Upper Paleolithic using the quadrangle 452 technique.

453 It should be noted that due to the lack of 454 access to the 3D image of other areas, we

\footnotetext{
2 (C) Markus Bader - MB-Software solutions
} 
455 used the 2D method for comparison. The 456 advantage of the two-dimensional method 457 is the simplicity of this method so that even 458 without the use of calculation I.D.S. only by 459 enclosing the point in a quadratic and 460 passing the axis through its center can the 461 differences be intuitively compared.

462 In this research, the 280 Iranian lithic 463 points were scanned in the Rock Mechanics

480 We measured the deviation of symmetry 481 lithic points in the middle Paleolithic sites 482 of Iran, Including Mirak, Chah e jam, 483 Mehran Plain, kouhrangh, and bandepay by 484 3D method (Table 3, 4).

485 In total, 280 points were selected from 486 Iranian sites for this research, which all 487 have been confirmed for having diagnostics 488 signs of Middle Paleolithic industries (e.g.,

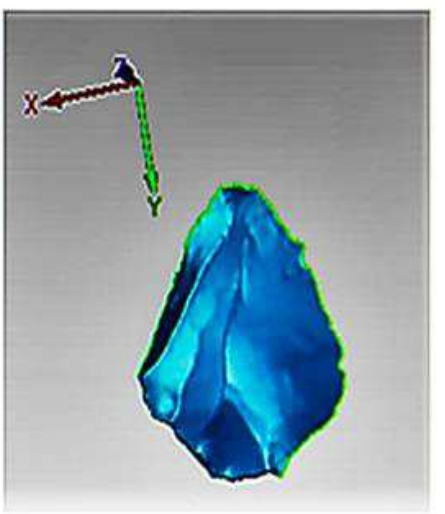

464 Laboratory, Tarbiat Modares University 465 (Tehran, Iran), using Optic Scan3D 466 Scanner, and Version 2.2. Once the 467 digitization was completed, 3D images 468 were analyzed and compared by Geomagic 469 software (version 2013). Also, a Marcus 470 Bader Ruler was used to bisect each lithic 471 point (version 5.1). Then, their symmetry 472 was measured in two- and three473 dimensional space.

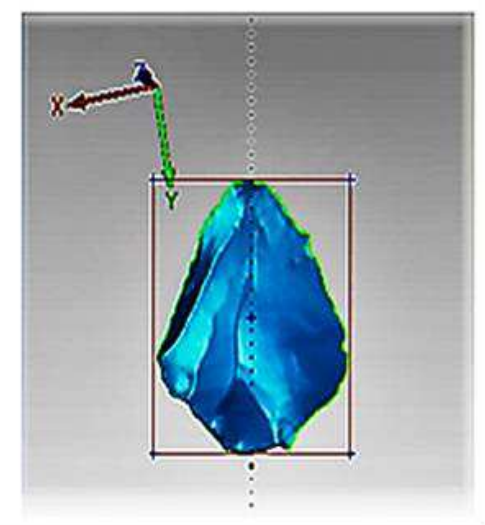

Figure 2. The quadrangle is halved, and each triangular lithic point is divided into two parts (Feizi et al., 2018).

\begin{tabular}{llllll}
\hline Site & Mirak & Chah-e Jam & Bandepey & Kuhrang & Mehran Plain
\end{tabular}

\begin{tabular}{lllllll}
\hline Number & 143 & 57 & 27 & 22 & 31 & \\
\hline Total & & & & &
\end{tabular}


505 In the second stage, considering the effect

506 of other morphological features such as

507 weight, length, width, and elongation on the

508 amount of penetration and drag, we

509 compared these features in 5 Iranian areas

510 with several areas inside and outside Iran.

511 These comparisons, which were performed

512 to observing possible evolutionary changes,

513 included comparing the points of the

514 Middle Paleolithic period with each other

515 as well as the points of the Middle and

516 Upper Paleolithic periods. Thus, the

517 morphological features related to the point's

518 aerodynamics were measured in the Iranian

519 sites and compared with other Paleolithic

520 sites outside Iran. These sites include Tor

521 Faraj (70-50k Ka) in Southern Jordan

522 (Groucutt, 2014), Kathu pan1 (291 45) in

523 southern Africa (Wilkins and Chazan, 2012

524 ), Kebara (60-50 Ka), Hayonim (100-90

$525 \mathrm{Ka}$ ), and Qafzehin (100-90 Ka) Levant

526 (Shea, 1988), and also Sibudu, Rose

527 Cottage in the Middle Stone Age in Africa

528 and Bouheben in the Middle Paleolithic of

529 the southwestern French (Lenoir, 2006), 530 some dart and arrowhead of the collections 531 of the American Museum of Natural 532 History (AMNH) (Thomas, 1978), and 533 finally, the points of the Neolithic sites of 534 Levant (Gopher, 1994). Table 2 535 summarizes the number of points 536 mentioned above that were chosen for 537 comparative analysis. These sites were not 538 selected at random because the main aim of 539 the selections is to cover an extensive 540 period. On the other hand, we selected sites 541 where the researchers measured the 542 morphological features of the lithic points, 543 and so it was possible to compare the 544 features. We compared different 545 dimensions of our points with experimental 546 points made by Rios-Garaizar (2016). Rios547 Garaizar's points are 24 Middle Paleolithic 548 points made using the Levallois technique 549 with flint from Morocco. These points fitted 550 the expected variability of Middle 551 Paleolithic points (Rios-Garaizar, 2016).

\section{2}

553

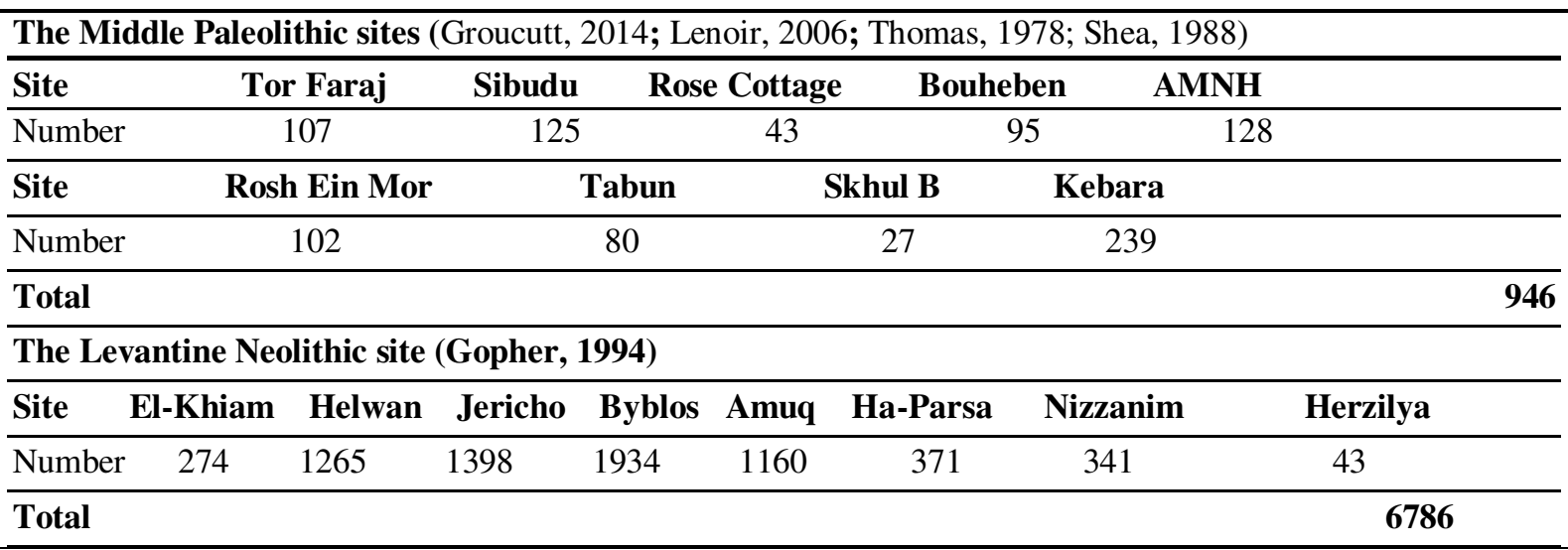

555

556 It is worth mentioning that, in this research; 558 methods are applied that had been used 557 except for symmetry, measurement 559 previously to measure the lithic points of 
560 sites out of Iran (Groucutt, 2014; Hardy et

561 al., 2013; Rios-Garaizar, 2016; Sisk and

562 Shea, 2011). In addition, the one-way

563 analysis of variance (ANOVA) was used to

564 determine whether there are any
565 statistically significant differences between 566 the means of TCSA and or other 567 morphological features such as weight, 568 length, and TCSP to compare the throwing 569 power of the points.

570

\section{Results}

572 We measured the deviation of symmetry 581 of asymmetrical ones compared to the total 573 lithic points in the middle Paleolithic sites 582 number of points that were studied on each 574 of Iran, Including Mirak, Chah e jam, 583 site. Figure 3 shows the mean of deviations 575 Mehran Plain, kouhrangh, and bandepay by 584 in these sites. The result is then compared 576 3D technique (Table 3, 4). Table 4 presents 585 with six sites outside Iran in the 2D method, 577 the summary statistics for all sites. 586 enclosing at a quadrat without calculating 578 Considering all the evidence (Tables 3), it 587 the I.D.S.The reason for using the 2D 579 seems that all five sites have a large number 588 method for other sites is the lack of access 580 of symmetrical points and a small number 589 to 3D images of them.

\begin{tabular}{|c|c|c|c|c|c|c|c|}
\hline site & Variable & $\mathbf{n}$ & dmax1 & dmax2 & dvag1 & dvag2 & RMS \\
\hline \multirow{2}{*}{ Mirak } & Mean & 133 & 2.88 & -2.81 & 0.70 & -0.69 & 0.89 \\
& Std. deviation & 133 & 0.28 & 0.39 & 0.24 & 0.29 & 0.38 \\
\hline Chah-e jam & Mean & 48 & 2.77 & -2.72 & 0.67 & -0.64 & 0.89 \\
& Std. deviation & 48 & 0.38 & 0.42 & 0.27 & 0.25 & 0.38 \\
\hline BandePey & Mean & 23 & 2.6 & -2.7 & 0.9 & -0.8 & 1.10 \\
& Std. deviation & 23 & 0.6 & -0.6 & 0.4 & -0.6 & 0.4 \\
\hline Mehran Plains. & Mean & 30 & 2.3 & -2.34 & 0.70 & -0.67 & 0.92 \\
& Std. deviation & 30 & 0.46 & 0.47 & 0.25 & 0.26 & 0.27 \\
\hline Kuhrang & Mean & 21 & 2.7 & -3 & 0.87 & -0.86 & 1.1 \\
& Std. deviation & 21 & 1.3 & 0.52 & 0.26 & 0.3 & 0.27 \\
\hline
\end{tabular}

Table 3.Summary of deviation analysis of our Iranian site. Dmax (+), the largest positive difference between two surfaces; dmax (-), the largest negative difference between two surfaces; dvag (+), mean the positive difference between two surfaces; dvag $(-)$, means the negative difference between two surfaces; RMS, root mean square of deviation.

\begin{tabular}{|c|c|c|c|c|}
\hline site & Number & Mean & $\begin{array}{c}\text { Standard } \\
\text { deviation }\end{array}$ & $\begin{array}{c}\text { Proportion of } \\
\text { unsymmetric/symmetric } \\
\text { points }\end{array}$ \\
\hline Mirak & 133 & 0.89 & 0.3 & 0.15 \\
\hline Chah-e jam & 48 & 0.87 & 0.25 & 0.2 \\
\hline BandePey & 23 & 1.09 & 0.3 & 0.2 \\
\hline Mehran Plains. & 30 & 0.86 & 0.3 & 0.2 \\
\hline Kuhrang & 21 & 1.1 & 0.45 & 0.09 \\
\hline Total & 225 & & & \\
\hline
\end{tabular}




\begin{tabular}{|c|c|c|c|c|}
\hline site & Number & Mean & $\begin{array}{c}\text { Standard } \\
\text { deviation }\end{array}$ & $\begin{array}{c}\text { Proportion of } \\
\text { unsymmetric/symmetric } \\
\text { points }\end{array}$ \\
\hline Mirak & 133 & 0.89 & 0.3 & 0.15 \\
\hline Chah-e jam & 48 & 0.87 & 0.25 & 0.2 \\
\hline BandePey & 23 & 1.09 & 0.3 & 0.2 \\
\hline Mehran Plains. & 30 & 0.86 & 0.3 & 0.2 \\
\hline Kuhrang & 21 & 1.1 & 0.45 & \\
\hline Total & 225 & & & 0.09 \\
\hline
\end{tabular}

Table 4. Descriptive statistics of the symmetry of lithic points in five sites in Iran.

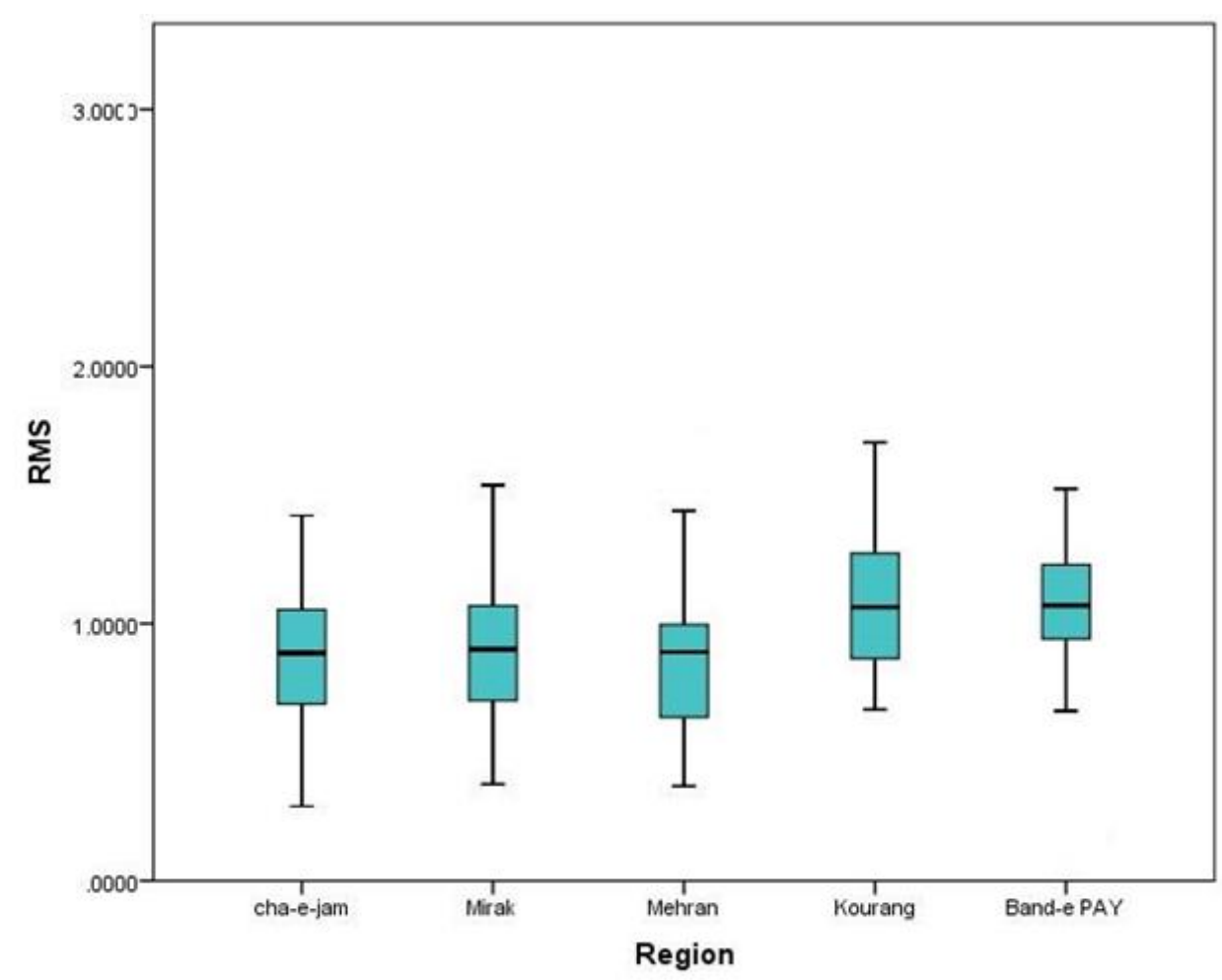

In the second stage, as can be seen from

\section{3}

604

605

606

607

608

609

610

611 than Tor Faraj and other Iranian sites

612 including Cha-e Jam, Mirak, and the

613 Mehran Plain. Nevertheless, the elongation
614 of all Iranian points is smaller or equal to 615 Tor Faraj's points. In other words, despite 616 the large weight, area, volume, TCSA..., 617 they have little elongation. Although, the 618 Sibudu, Rose Cottage, and Bouheben's 619 points are less elongated, despite being 620 comparable in height to Iranian and Tor 621 Faraj's points.

622 According to these morphological 623 features, we believe that Iranian points, the 624 same as Tor Faraj's points, do not have the 
625 capacity of throwing. The experimental use

627 points proved this claim (Mehrpoor 628 Moghadam, 2009). In the thesis, a point 629 was constructed with the average 630 morphological features of Mirk points. This 631 point was attached to three hafts with 632 different weights of $500 \mathrm{~g}, 800 \mathrm{~g}$, and 1200

$633 \mathrm{~g}$ and was thrown to a Lamb meat several 634 times. The launches were done from 635 different distances of 10 meters and fewer. 636 Despite the contact with the meat, these 637 spears did not penetrate, and only a scratch 638 effect was seen (Mehrpoor Moghadam, 639 2009).

640 Based on the above results, one reason for 641 this could be the lack of the ability to create 642 perfect symmetry in the points, and 643 insufficient elongation due to the proximity 644 of length and width values is a main factor 645 in increasing the drag and decreasing
646 penetration depth. On the other hand, 647 approximately equal in width to the length 648 of the arrowhead is the main factor in their 649 durability (Van Buren, 1974). However, 650 based on the Mummy Cave tip, Hughes 651 shows that there is a trade-off between 652 increasing penetration depth or durability 653 (Hughes, 1998). So, he believes most 654 projectiles will be designed to increase 655 penetration, so unlike the thrusting spears, 656 they are less durable (Hughes, 1998). The 657 South African Middle Stone Age points in 658 Sibudu, Rose Cottage and the Middle 659 Paleolithic points in the South West of 660 France supported this claim (See Table 5). 661 Nevertheless, the points that were made by 662 Rios-Garaizar demonstrated that at least 663 some Mousterian points could be used as 664 throwing spear tips (Rios-Garaizar, 2016). 665 It is worth bearing in mind that Rios666 Garaizar used eight of his experimental 667 points to perform throwing motions.

\begin{tabular}{|c|c|c|c|c|c|c|c|}
\hline Site & $\begin{array}{l}\text { Length } \\
(\mathrm{mm}) \\
\end{array}$ & $\begin{array}{l}\text { Width } \\
\text { (mm) } \\
\end{array}$ & $\begin{array}{l}\text { Thickness } \\
(\mathbf{m m})\end{array}$ & $\begin{array}{l}\text { Weight } \\
(\mathrm{gm})\end{array}$ & $\begin{array}{l}\text { TCSA } \\
(\mathbf{m m 2}) \\
\end{array}$ & Elongation & Flattening \\
\hline Bouheben & 57.4 & 32.1 & 10.7 & 18.9 & 177 & 1.8 & 3 \\
\hline Sibudu, final MSA & 46.9 & 27.7 & 7.3 & 10.7 & 116.2 & 1.7 & 3.8 \\
\hline Sibudu, RSp-MOD & 41.8 & 27 & 8.1 & 11.9 & 117.7 & 1.6 & 3.3 \\
\hline $\begin{array}{l}\text { Sibudu, layers below } \\
\text { RSS }\end{array}$ & 45.3 & 28.7 & 9.6 & 14.2 & 139.4 & 1.5 & 3 \\
\hline Rose Cottage & 36.6 & 21.4 & 7.1 & 5.2 & 74 & 1.7 & 3 \\
\hline
\end{tabular}

669 


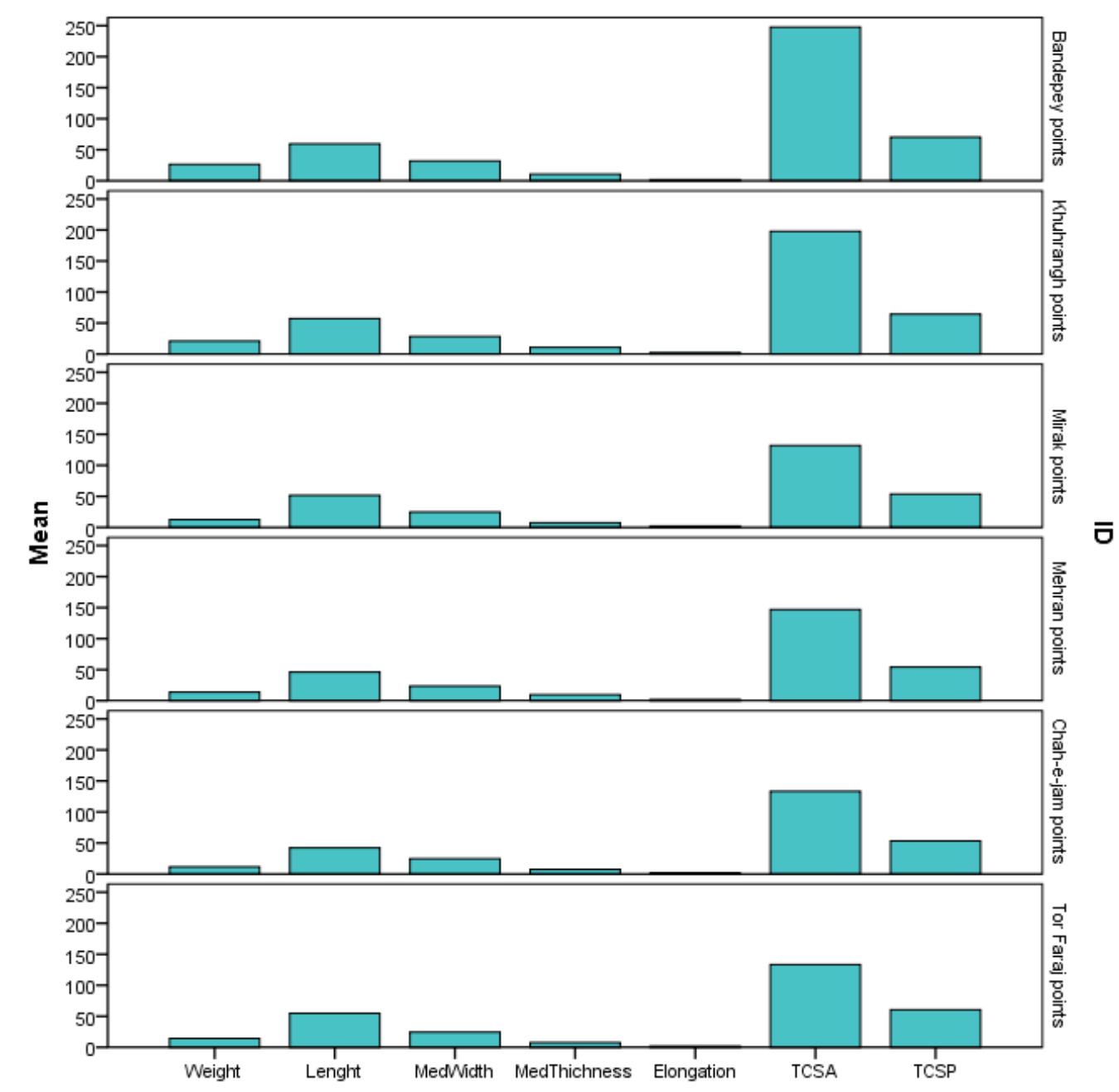

Figure 4. Comparison of morphological features of Mirak, Chah e jam, Mehran Plain, kouhrangh, bandepay, and tour Faraj points

679 Therefore, we need to know whether or not

680

681

682

683

684

685

686

687

688

689

690

691

692

693

694

695

any differences of importance existed between the mean TCSA in our middle Paleolithic points with Rios-Garaizar's projectiles. We tested this possibility with an ANOVA (one-way). The reason for this is the comparison of the throwing power of our Iranian Paleolithic points with his experimental points. Because we know that the TCSA has a great effect on the throwing power, and Rios-Garaizar has concluded by testing its points that they do have this ability due to the large cross-section. So if the average cross-sectional area of our 709 points is equal or significantly smaller than 710 his projectiles, our points have probably 711 thrown capacity. The calculated value of $F 712$
696 was 14.93 , and the significance level $(S=$ 697 0.000). The null hypothesis (no significant 698 difference) is therefore rejected, suggesting 699 that the difference between the TCSA 700 means is significant. Results of the 701 ANOVA further indicated a need to 702 compare the mean of TCSA for all sites. 703 The least significant difference (LSD) test 704 helps to identify the TCSA whose means 705 are statistically different. Results of the 706 LSD tests indicate that Rios-Garaizar's 707 projectiles have a statistically significant 708 difference with the points from Mehran 9 Plain, Bandepey, and Kuhrang site. In other 10 words, as can be seen from the Boxplots 1 below (Figure 5), the points of these three 12 areas have a larger TCSA. While the rest of 
713 the points - Mirak and Chah-e-jam's points

714 - are similar to Rios-Garaizar's

715 experimental examples (Fig. 4). It seems

716 possible that the reason for the large TCSA

717 in the two sets of Bandepey and Kuhrang

718 site is on-site availability and abundance of

719 the raw material (Roustaei, 2010; Vahdati

720 Nasab et al., 2017), which has caused tool

721 makers to pay less attention to shaping their

722 tools and deviate too much from symmetry

723 (Feizi et al., 2019). In addition to Point

724 morphological features, the physical

725 characteristics of shafts, such as their length

726 can be decisive (Rios-Garaizar, 2016), so

727 that the shaft has a direct effect on the

728 penetration depth (Salem and Churchill,

729 2013). Interestingly, the Rios-Garaizar

730 experimental shafts, are taller $(220,200$,

$731 \quad 180$ lengths). In addition, Solutrean

732 shoulder points are other examples that

733 look asymmetrical but act well due to the

734 use of the shaft (Chadelle et al., 1986). In

735 these cases, it seems that joining the shaft

736 and point in the best possible way is the

737 main reason for the suitable functioning. In

738 these cases, According to the quadrangle
739 technique, it can be said that the axis of the 740 more symmetrical part with the axis of the 741 shaft adjusts, and the more asymmetrical 742 enters the shaft (Figure 6).

743 The left and right points are adjusted around 744 the shaft axis so that the tool is 745 approximately the same shape, size, weight, 746 and height on both sides, and as the axis 747 elongate, the destructive power of the 748 weapon increases (Feizi et al., 2018).

749 Thus, the smaller the deviation from the 750 symmetry and the more its axis of 751 symmetry coincides with the shaft axis, the 752 more symmetrical it is, the greater the 753 accuracy of the throw (Salem and 754 Churchill, 2013).

755 In general, we do not have information 756 about our shaft lengths. Based on this, we 757 ignored the shaft and only research the 758 ability to throw our points. Given the 759 morphological features mentioned, we can 760 say that the Middle Paleolithic points 761 cannot be thrown.

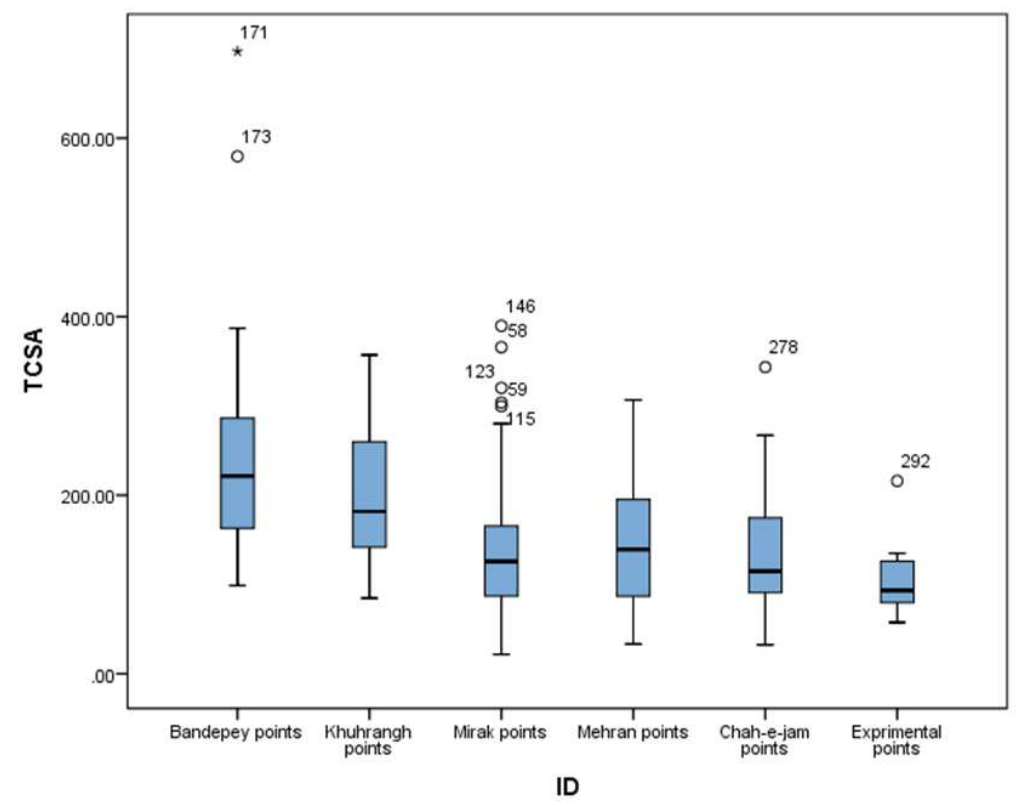

Figure 5. Comparison of TCSA of Mirak, Chah e jam, Mehran Plain, kouhrangh, bandepay, and Experimental points 
Figure 6. The axis of symmetry of the Solutrean shouldered points approximate the main axis of the shaft.

768 In the Upper Paleolithic, for the first time, 791 evident that a perfect projectile has an 769 Homo sapiens made the dart (Shea, 2010), 792 optimal shape. However, the question 770 and the arrowhead as a weapon was 793 stands: what morphological changes caused 771 associated with the darts (Shea, 2006), 794 such a success in the Upper Paleolithic 772 although, later replaced it (Hughes, 1998). 795 points?

773 Some scientists believe that the ability to

774 make throwing weapons eventually enabled

775 Homo sapiens to leave out of Africa and 776 enter temperate western Eurasia (Shea,

777 2013). Shea is among archaeologists who

778 believe that cross-sectional area is a vital

779 factor in the ballistic power of the weapon

780 (Shea, 2006). Statistically, Shea shows that

781 the TCSA values of the points are

782 significantly different between the two

783 types of stone projectile points (spear-

784 thrower dart tips and arrowheads) and spear

785 points. $\mathrm{He}$ obtained this result by

786 comparing the TCSA values of stone

787 projectile points to hypothetical Middle and

788 Upper Paleolithic stone projectile points

789 from Africa, the Levant, and Europe.

790 Aerodynamically, at the moment, it is

796 In 1976, Thomas compared the 128 797 numbers of darts (10 number) and 798 arrowheads (118 number). In line with 799 Shea's aim, we need to know whether or not 800 any differences of importance existed 801 between the mean TCSA in our middle 802 Paleolithic points with Thomas's 803 projectiles. We tested this possibility with 804 an ANOVA (one-way). The calculated 805 value of $F$ was 41.46 , and the significance 806 level $(S=0.000)$. The null hypothesis is 807 therefore rejected, suggesting that the 808 difference between the TCSA means is 809 significant. Results of the ANOVA further 810 indicated a need to compare the mean of 811 TCSA for all sites. The least significant 812 difference (LSD) test helps to identify the 
813 TCSA whose mean are statistically

814 different. Results of the LSD tests indicate

815 that Thomas's projectiles have a statistically

816 significant difference from our Iranian

817 points, although darts and arrowheads do

818 not differ from each other significantly

819 (Fig. 7). Thus, our Iranian middle points

820 have larger TCSA than Thomas's darts and

821 arrowheads.

822 In addition, we calculated the means of

823 other morphological features measured by

824 Thomas. As can be seen in Table 6, the

825 darts have been taller, thicker, and have

826 wider tips than the arrowheads, whereas all

827 of them are much lighter than the Middle
828 Paleolithic points. However, elongation and

829 flattening are approximately equal

830 (Appendix Table 1, 2, and 7). In addition,

831 arrowheads have shorter and smaller (in

832 diameter) fore shafts than the darts.

833 As can be seen in Table 8, in the Neolithic 834 Levant sites, the projectile points have the 835 same average length as the Middle and 836 Upper Paleolithic points. In contrast, they 837 have less width and thickness. It should be 838 noted that we calculated the means of 839 morphological features of the Levantine 840 points that were published by Gopher 841 (1994).

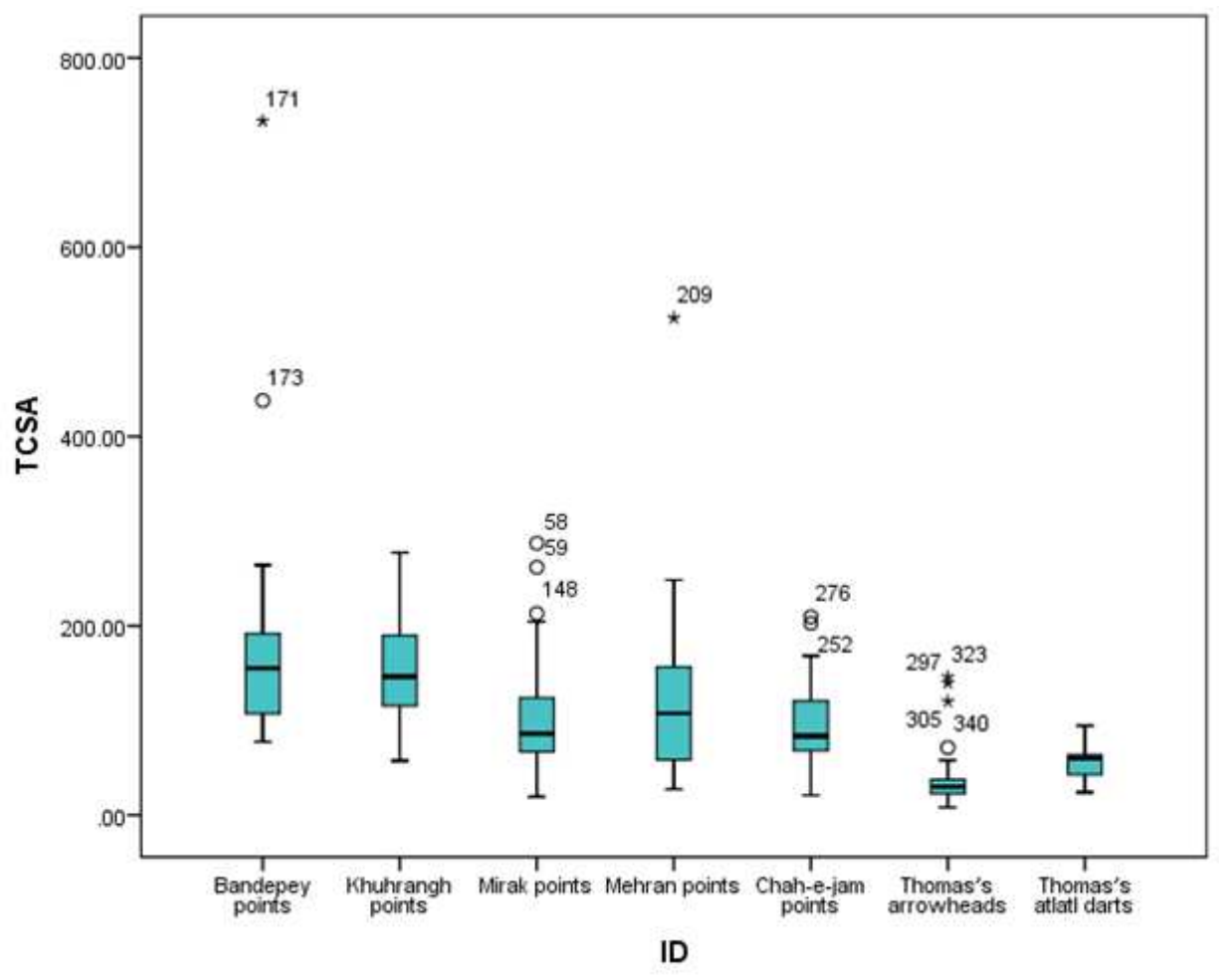

Figure7. Comparison of TCSA of Mirak, Chah e jam, Mehran Plain, kouhrangh, bandepay, and Thomas's Dart and arrowhead 


\begin{tabular}{ccccccccc}
\hline Tools & $\mathbf{n}$ & $\begin{array}{c}\text { Length } \\
(\mathbf{m m})\end{array}$ & $\begin{array}{c}\text { Width } \\
(\mathbf{m m})\end{array}$ & $\begin{array}{c}\text { Thickness } \\
(\mathbf{m m})\end{array}$ & $\begin{array}{c}\text { Neck } \\
\text { Width(mm) }\end{array}$ & $\begin{array}{c}\text { Weight } \\
(\mathbf{g m})\end{array}$ & $\begin{array}{c}\text { TCSA } \\
(\mathbf{m m})\end{array}$ & $\begin{array}{c}\text { Foreshafte } \\
(\mathbf{m m})\end{array}$ \\
\hline Dart & 10 & 46.2 & 22.9 & 4.9 & 13.7 & 4.38 & 56 & 105 \\
\hline Arrowhead & 132 & 31.1 & 14.7 & 4 & 10 & 2.07 & 33 & 71 \\
\hline
\end{tabular}

Table 6. The morphological measurements for arrowheads and dart tips Tomas's sets

851

852

857

\section{Discussion and Conclusion}

859 The third dimension of the lithic points is a 860 critical factor in creating symmetry. It is 861 necessary but not sufficient to have a two862 dimensional symmetry (length and width), 863 although the third dimension seems 864 determinative. It means that in addition to 865 symmetrical appearance, realistic 866 symmetry is also necessary for the useful 867 function of a lithic point (Feizi et al., 2019).

\begin{tabular}{llll}
\hline Tools & n & Elongation & Flattening \\
\hline Dart & 10 & 2.02 & 4.7 \\
\hline Arrowhead & 132 & 2.12 & 3.7 \\
\hline
\end{tabular}

Table 7. The measurements of elongation and flattening for arrowheads and dart tips.

\begin{tabular}{ccccccc}
\hline sample & $\begin{array}{c}\text { Length } \\
(\mathbf{m m})\end{array}$ & $\begin{array}{c}\text { Width } \\
(\mathbf{m m})\end{array}$ & $\begin{array}{c}\text { Thickness } \\
(\mathbf{m m})\end{array}$ & $\begin{array}{c}\text { TCSA } \\
(\mathbf{m m})\end{array}$ & Elongation & Flattening \\
\hline Helwan points & 32.41 & 9.4 & 3.1 & 20 & 2.5 & 4.2 \\
\hline Jericho points & 52.04 & 14.4 & 4.3 & 31 & 3.6 & 3.3 \\
\hline Byblos points & 49.83 & 13 & 4.1 & 27 & 3.8 & 3.2 \\
\hline Amuq points & 52.85 & 12.3 & 4 & 26 & 4.3 & 3.1 \\
\hline Ha-Parsa points & 28.8 & 11.2 & 3.3 & 18 & 2.6 & 3.4 \\
\hline Nizzanim points & 31.83 & 10.9 & 3.6 & 20 & 2.9 & 3.03 \\
\hline Herzilya points & 28.24 & 12.2 & 3.7 & 23 & 2.3 & 3.3 \\
\hline
\end{tabular}

Table 8. The morphological measurements for the arrowheads of the Neolithic Levant (Gopher, 1994).

868 Thus, both sides of the lithic point must 869 be in similar conditions regarding the 870 removal depth. Although despite the 871 existence of a symmetrical appearance, 872 some lithic points do not have realistic 873 symmetry. Several unsymmetrical points 874 have been recorded in the Iranian sites (Fig. 875 8). It was shown that the more conscious 876 attention is, the more regular the pattern 877 preparation is. Accordingly, the lithic point 878 is more symmetric (Feizi et al., 2018) (Fig. 879 9). 
880

881

882

883

884

891

892

893

894

895

896

897

898

899

900

901

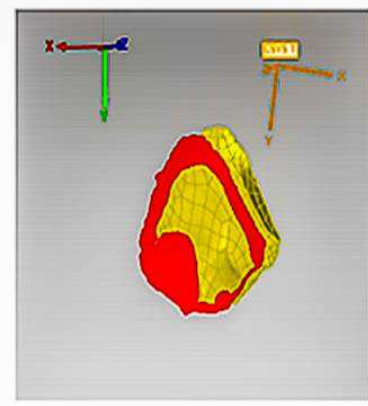

Figure 8. The unsymmetrical points. (The dorsal side of the CAD (gold color) and mesh (red color) models overlap) (Feizi et al., 2018).
886

887

888

889

890

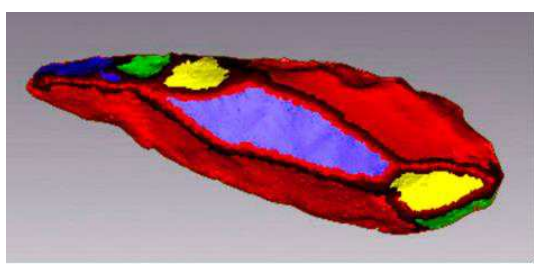

Figure 9. The symmetrical point with a regular pattern in terms of ridges and troughs (Areas of the same color have the same depth and) prominence (Feizi et al., 2018).
912

913

914

915 The quadrangle technique could reveal a

916 similar pattern for deviation of symmetry in

917 the Middle Paleolithic points. It seems

918 likely that Neanderthals did not attempt to

919 create specific symmetrical tools. To put it

920 another way, they have been convinced of

921 general symmetry (Feizi et al., 2019). When

922 these lithic points are located in the

923 quadrangle that measures the deviation of

924 symmetry, the axis is passing the left or
902 symmetry. In all sites, retouch was used for 903 achieving symmetry of the edges and 904 shaping the lithic points, particularly in 905 group 1 (Table 9). To sum up, a common 906 pattern of deviation from symmetry is 907 apparent in each group, and this suggests a 908 difference between groups in the amount of 909 conscious attention which can be the result 910 of access to raw materials (Feizi et al., 911 2019).

\begin{tabular}{|c|c|c|c|}
\hline site & $\mathrm{N}$ & Means & Std \\
\hline Mirak & 148 & 4.02 & 0.14 \\
\hline Chah-e jam & 58 & 5.18 & 0.18 \\
\hline BandePey & 27 & 3.4 & 0 \\
\hline Mehran Plains. & 31 & 4.66 & 0.19 \\
\hline Kuhrang & 23 & 3.09 & 0.26 \\
\hline
\end{tabular}
et al., 2019). 

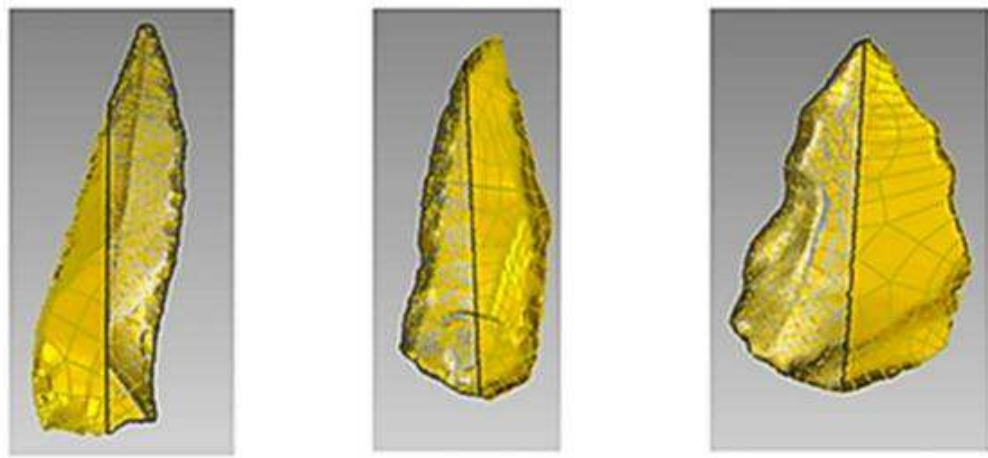

Figure 10-1. In the middle Paleolithic, hominids had not carefully performed symmetry (Feizi, 2018).

937

938 939

940

941

942
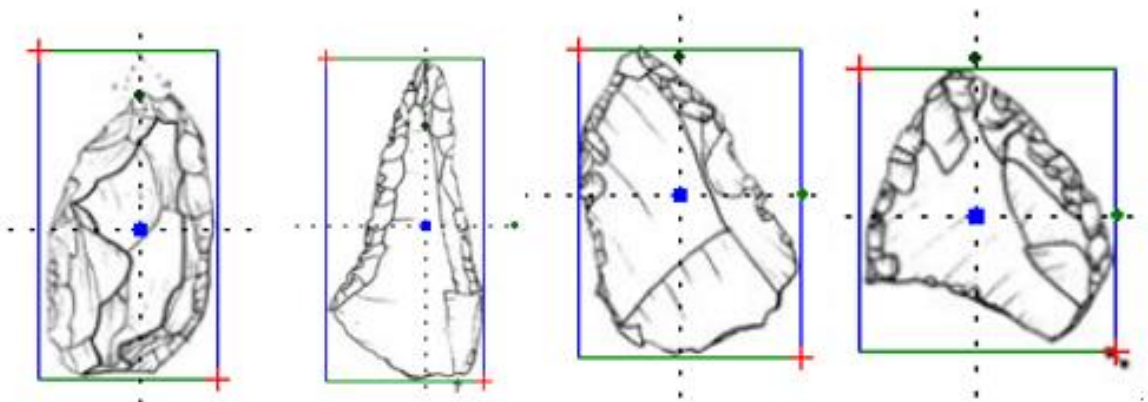

Figure 10-2. The deviation from symmetry in the Northern Iberian Peninsula MiddlePaleolithic Mousterian Point (Rios-Garaizar, 2016).

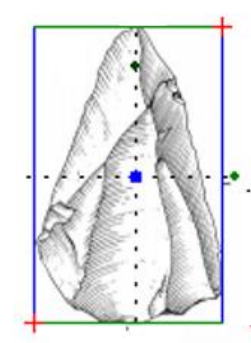

1

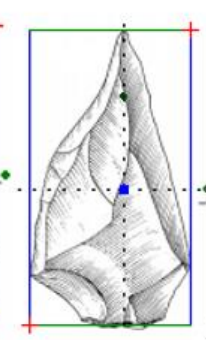

2

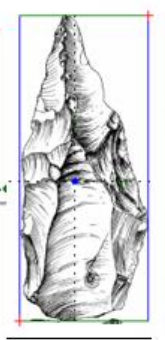

3

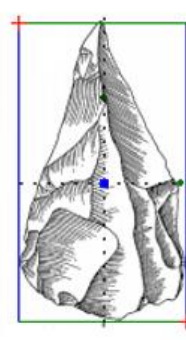

4

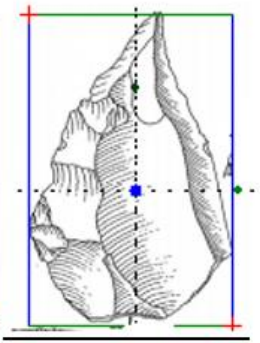

5

Figure10-3. Examples of Middle Paleolithic points from northeast Africa and southwest Asia. 1, 2: Jebel Katefeh, 3. Aybut al Auwal, Oman. 4, 5: Nazlet Khater, Egypt (Groucutt, 2013).

943 In general, the situation looks completely 947 cave, Galeh ghosheh site) shows that a 944 different in the Upper Paleolithic. The study 948 serious change has been made in the 945 of projectile points of the sites mentioned 949 administration of symmetry in the Upper 946 above in Iran (Yafteh cave, Arjaneh, Boof 950 Paleolithic points (For example, Fig. 11). 


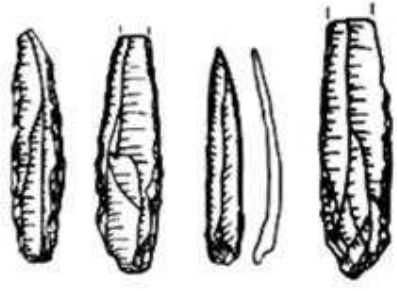

1

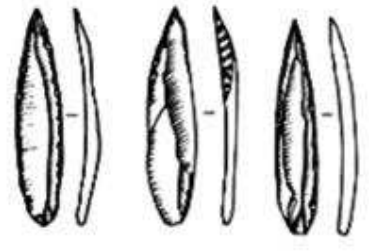

2
953

954

955

956
Figure 11. Several symmetrical projectile points (Arjaneh point) in 1. Qaleh Gosheh 1(Conard, et al., 2009), and 2. Yafteh cave (Hole, 1970).
957 In addition, the comparison of the Iranian

958 Middle Paleolithic projectile points with 959 those from outside Iran such as Levantine 960 points (Emireh, Umm el Telel, Ksar Akil, 961 El Wad points), (Shea, 2013: 141), the West

962 European points (Chatelperronian,

963 Gravette, Font Robert, Solutrean), Middle

964 Stone Age of Africa (symmetrical 965 triangular flakes, foliate bifaces, unifacial 966 points, tanged points) demonstrate similar 967 patterns.

968 Using the quadrangle technique for the 969 Upper Paleolithic points indicates that 970 symmetry has evolved a high percentage 971 compared to the Middle Paleolithic period.

972 Interestingly, it seems that Homo sapiens 973 paid special attention to the practical 974 aspects of symmetry. Accordingly, they
975 made the symmetrical points that the axis of 976 symmetry generally crosses over the 977 midline of, and its two sides have the same 978 morphological figures and thickness (Fig. 979 12). Although there are many 980 unsymmetrical points at this time, it seems 981 that increasing the cognitive capacity of 982 symmetry implementation causes to make a 983 perfect projectile since the Middle 984 Paleolithic period. In the Upper Paleolithic 985 period, all points are not projectile or spear 986 points; they might be knives or have other 987 functions (Newman and Moore, 2013). 988 Therefore, not all of the Upper Paleolithic 989 points need to have optimal symmetry. 990 However, as outlined earlier, perfect 991 symmetry is impossible in reality, and there 992 is always a numeric value as the deviation 993 of symmetry. 


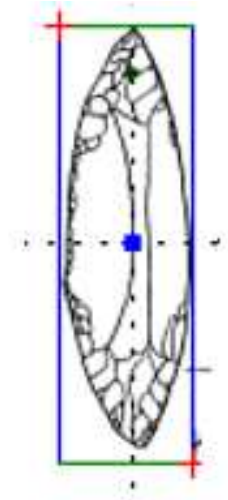

1

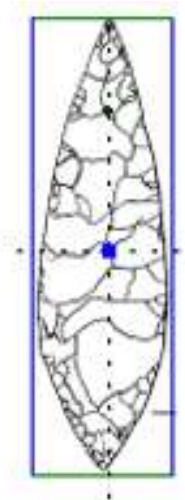

2

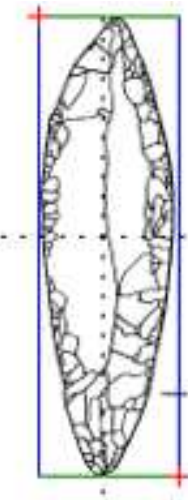

3

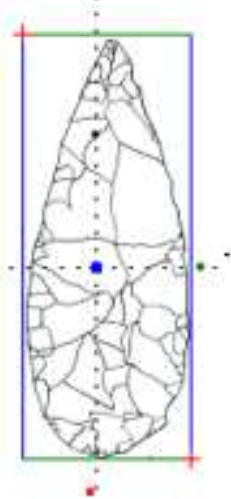

4

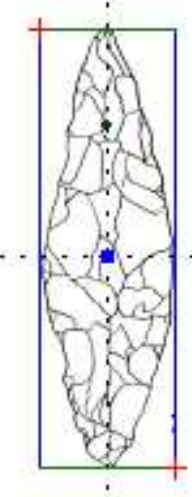

5

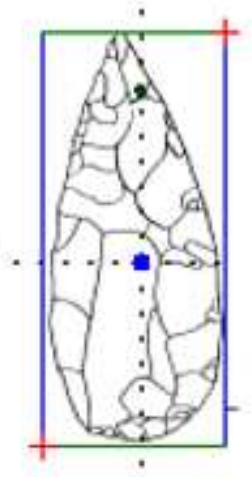

6
994

995

996

997

998

999

1000 In the Upper Paleolithic period, it seems 1026

1001 that balance and realistic symmetry are 1027

1002 created. The reason for this is that Homo 1028

1003 sapiens started to pay attention to the 1029

1004 thickness of lithic points. Tool efficiency 1030

1005 may explain why Homo sapiens focused 1031

1006 their attention on making symmetrical

1007 points. Unfortunately, we did not have

1008 enough Projectile points to measure 3D

1009 symmetry for the Upper Paleolithic points.

1010 However, the indirect documents such as

1011 the decreasing thickness, weight, width,

1012 and increasing degree of their preparation

1013 cause the possibility of optimal symmetry.

1014 Accordingly, we believe that symmetry 1040

1015 was evolving in the Paleolithic period, and 1041

1016 the deviation of symmetry affects the 1042

1017 performance of throwing. In this research, 1043

1018 in addition to symmetry, other 1044

1019 morphological features such as elongation, 1045

1020 area, weight, and cross-section were 1046

1021 measured. In the later period, it seems that 1047

1022 this problem can be solved. Our reason is 1048

1023 that for making a perfect projectile to 1049

1024 reduce aerodynamic drag, we need a 1050

1025 cylinder body, a blunt nose, and two sharp 1051 trailing edges (Roper, 2008) like a fish, Dartfish, or maybe a dart. Another critical factor for the symmetrical projectile is that if the maximum cross-section area is approximately in the middle length, the drag will be the least (Sears, 1974).

032 The evidence shows that generally, arrowheads and darts are perfect projectiles (Thomas, 1978); as we can be seen in Table 7 , the mean of darts and arrowheads elongation respectively are $2 / 02$ and $2 / 21$ with the cross-sections that respectively are 56 and 33. A simple mathematical proportion proves that if Mirak's points with this mean $(=51 / 9)$ are projectiles, the means of the elongation will be $3 / 53$ approximately. At the same time, this is equivalent to 1.99 for Mirak's points. On the other hand, as can be seen in Appendix Tables 1, 2, in the Middle Paleolithic, generally cross-section area is not located at the middle length of points; as a result, the drag could not be minimum. Thus, the shape of the trajectory is not standard, and throwing is not distance hunting or executed correctly. 
1053 What is interesting in this data is that in 1097 1054 Jericho and Amuq projectile points (Table 1098 1055 8), The Neolithic sites of the Levant, which 1099 1056 are about the same length as the Mirak's 1100 1057 point, are more elongated and much 1101 1058 thinner. Data from Appendix Tables 1, 2, 1102 1059 and Table 5 can be compared with the data 1103 1060 in Table 8. While the result in most Middle 1104 1061 Paleolithic sites (including Mirak, Chah-e- 1105 1062 jam, Khuhrangh, Bandepey, and Mehran in 1106 1063 Iran, and Torfaraj in Jordan and Bouheben 1064 in the southwestern of French, and middle 1065 Stone Age of Sibudu and Rose Cottage in 1066 Africa) is quite contrary. In these Middle 1067 Paleolithic sites, we do not have the points 1068 with geometric proportions and enough 1069 elongation to overcome the drag. Based on 1070 a t-test, Thomas showed that arrow fore 1071 shafts are undeniably smaller (in diameter) 1072 than dart fore shafts (Thomas, 1978). 1073 However, morphologically, the darts are 1074 larger than the arrowheads and have longer 1075 fore shaft than arrowheads. This 1076 relationship may be due to the created 1077 proportion and the throwing power of the 1078 points; the subject needs further 1079 investigation.

1080 on the other hand, based on experimental 1124

1081 data, some researchers focused on fracture 1125

1082 mechanics to identify projectile use and 1126 1083 penetrating characteristics (please see 1127 1084 Fisher et al., 1984; Odell and Cowan, 1986; 1128 1085 Dockall, 1997; Plisson, 2005; Iovita et al., 1129 1086 2013; Rots and Plisson, 2014; Coppe and 1130 1087 Rots. 2017). By Dockall, There are unique 1131 1088 fracture patterns of the projectile (Dockall, 1132 1089 1997), which can be the result of 1133 1090 attachment to the handle or the impact of 1134 1091 physical contact (a Kufel-Diakowska, 1135 1092 2016). However, researchers warn that 1136 1093 large archaeological samples and 1137 1094 examination of all types of wear a projectile 1138 1095 in these samples are needed to identify the 1139 1096 projectile's performance from fractures 1140
(Rots and Plisson, 2014). Accordingly, using an attribute-based approach, Coppe and Roth (2017) show that there is a clear difference between the bow and the spearthrower in terms of the fracture surface as a result of the type of contact. So that the distal location of an arrow is damaged by contact with bone, while due to contact with skin, the mesial location of a dart point is fractured (Coppe and Rots, 2017).

In ballistic, the fact that the target is also a criterion and will significantly affect the results (Rots and Plisson, 2014). Thus, a hard target needs a perfect projectile. So that, an oblique contact leads to the formation of the mesial scars, whereas, an oblique contact itself is a consequence of a deviation of the projectile (spin calibration) (Coppe and Rots, 2017). The deformation and fracture of the target as a contact problem between the target and the projectile is essential (Rodriguez-Millan et al., 2018). In addition, one of the most important aspects of the geometric design of a projectile is predicting the penetration depth (Wingrove, 1973). It seems that the penetration depth of an arrow is more than the dart (Hughes, 1987). In addition, experimentally, the spin of an arrow is much more stable than a dart, while an arrow is less likely to hit the target under this angle that will cause a dart to hit the skin under an oblique angle (Coppe and Rots, 2017). It should be noted that the cross-sectional area, the shape, and the mass-velocity relationship of a stone tip affected its penetration depth (Hughes, 1987). However, in experimental throws on an animal carcass, researchers show that in terms of penetration, retouched and shaped points had almost the same performance as unretouched and unformed points (Odell and Cowan, 1986 and Churchill, 1993), although, these results are intragroup and 
1141 relate to only certain types of points with 1173

1142 almost identical morphology. For 1174

1143 Andrefsky, the production of formal tools 1175

1144 needs more effort and was usually done 1176

1145 when raw material occurred in low 1177

1146 abundance or at some distance. Proximity 1178

1147 to raw material leads to the use of lithic 1179

1148 tools over a short period because tool 1180

1149 makers do not need to exert much effort in 1181

1150 the production of new tools, nor do they 1182

1151 need to save material by making small tools 1183

1152 (Andrefsky, 1994). In intragroup points, for

1153 example, Middle Paleolithic points in our

1154 research areas, retouch was used for 1185

1155 achieving symmetry of the edges and 1187

1156 shaping the lithic points, particularly in 1188

1157 Mirk, Chah Jam, and Mehran plain. In these 1189

1158 sites, toolmakers attempted to reduce the 1190

1159 deviation of symmetry using retouch. So in 1191

1160 the three sites, the relatively great distance 1192

1161 to the raw material sources required saving 1193

1162 raw materials and manufacturing formal 1194

1163 and symmetrical points (Feizi et al., 2019). 1195

1164 During the evolution of the point, 1196

1165 Symmetry points improve projectile 1197

1166 precision and flight dynamics (Churchill, 1198

1167 1993). The most important reason is that 1200

1168 more symmetrical points have a more 1201

1169 regular flight path than very asymmetric 1202

1170 points. So that mass imbalance at the distal 1203

1171 end of the projectile or shape asymmetries 1204

1172 at the tip leads to an erratic flight path

1205

1206 Author

Contributions: 1219

1207 Conceptualization, N.F. Supervision, 1220

1208 H.V.N.

1221

1222

1209

1210 Funding: This research is financially 1223

1211 supported by the Iran National Science 1224

1212 Foundation (INSF) for postdoctoral

1213 research, grant number: 97/S/5904.

1214 Acknowledgments: The authors would 1227

1215 like to thank the anonymous reviewers for

1216 their constructive comments. We also

1217 would like to express our gratitude towards 1229

1218 Dr. K. Roustaei and Dr. A. Javanmard 1230
1225

1226

(Salem and Churchill, 2016). In addition, the more symmetrical point has fewer protrusions (Feizi et al., 2019), which causes to decrease in the drag coefficient and increases its penetration depth (Hughes, 1987). Accordingly, it seems that (2017), the proper symmetry and more regular flight trajectories of an arrow causes to reduce its spin and its deflection and decreasing the oblique contact with the target.

In sum, the law of projectile motion alongside our mathematical method convinced us that significant changes had occurred in the morphology of points since the Middle Paleolithic period. Some morphological changes, such as the least deviation of symmetry and the proportion between width - length and width-thickness that could be among the factors of the drag reduction, occurred in the Upper Paleolithic. Accordingly, in the Middle Paleolithic period, the minimal number of lithic points may have such features. In contrast, we think that the points gradually have become a projectile point for better survival of Homo sapiens. Most of all, this development could be the cognitive development of Homo and, in particular, modern humans.

Zadeh for their generosity to allocate their archaeological materials for this research. The scanning process took place in the Rock Mechanic Lab, Mining Department, Tarbiat Modares University; we thank the lab crew for their help and support.

Conflicts of Interest: The authors declare no conflict of interest.

\section{References}

Adams, R., Crouse, W., Carl Jr, E. and Abelson, P.H. eds., 1960. Mac Graw-Hill Encyclopedia of 
1231 Science and Technology: An International 1273

1232 Reference Work in 15 Volumes Including an Index. 1274

1233 Spir-Tou. McGraw-Hill Book Company.

1234 Andrefsky Jr, W., 1994. The geological 1275

1235 occurrence of lithic material and stone tool 1277

1236 production

1278

1237 strategies. Geoarchaeology, 9(5), pp.375- 1279

1238391.

1239 Ang, D.G., 2013. Shape and size matter for

1240 projectile drag. J. Adv. Undergrad. Phys. 1282

1241 Lab. Invest, 1(2).

1283

1284

1242 Bourot, J.M., 1974. On the numerical 1285

1243 computation of the optimum profile in 1286

1244 Stokes flow. Journal of Fluid 1287

1245 Mechanics, 65(3), pp.513-515.

1288 Dockall, J.E., 1997. Wear traces and

1246 Carlucci, D.E., and Jacobson, S.S., 2018. 1289

1247 Ballistics: theory and design of guns and 1290

1248 ammunition. CRC Press.

1291

1292

1249 Churchill, S.E. and Rhodes, J.A., 2009. The

1250 evolution of the human capacity for "killing 1293

1251 at a distance": the human fossil evidence for 1294

1252 the evolution of projectile weaponry. In The 1295

1253 evolution of hominin diets (pp. 201-210). 1296

1254 Springer, Dordrecht.

1297

1298

1255 Churchill, S.E., 1993. Weapon technology,

1256 prey size selection, and hunting methods in 1299

1257 modern hunter-gatherers: Implications for 1300

1258 hunting in the Paleolithic and 1301

1259 Mesolithic. Archeological Papers of the 1302

1260 American

Anthropological 1303

1261 Association, 4(1), pp.11-24.

1304

1262 Clarkson, C., 2016. Testing archaeological

1305

1263 approaches to determining past projectile 1306

1264 delivery systems using ethnographic and 1307

1265 experimental data. In Multidisciplinary 1308

1266 approaches to the study of Stone Age 1309

1267 weaponry (pp. 189-201). Springer, 1310

1268 Dordrecht. https://doi.org/10.1007/978-

1269 94-017-7602-8_13

1311 Ghasidian, Elham, 2012, "Rostami Culture 1312 and the Cultural Characteristics of Modern

1270 Delpiano, D., Zupancich, A. and Peresani, 1313 Paleolithic in Zagros Settlements", Eighty

1271 M., 2019. Innovative Neanderthals: Results 1314

1272 from an integrated analytical approach 1315 applied to back stone tools. Journal of Archaeological Science, 110, p.105011.

Conard, N.J., Ghasidian, E. and Heydari, S., 2009. The open-air Late Paleolithic site of Bardia and the Paleolithic occupation of the Qaleh Gusheh sand dunes, Esfahan Province, Iran. British Archaeological Research International Series, 1968,

Coppe, J. and Rots, V., 2017. Focus on the target. The importance of a transparent fracture terminology for understanding projectile points and projecting modes. Journal of Archaeological Science: Reports, 12, pp.109-123.

projectile impact: a review of the experimental and archaeological evidence. Journal of Field Archaeology, 24(3), pp.321-331.

Feizi, N., Vahdati Nasab, H. and Wynn, T., 2018. Consider the third dimension: A new approach for measuring the symmetry of the middle Paleolithic points of the Mirak Site. Comptes Rendus Palevol, 17(6),

Feizi, N., Vahdati Nasab, H. and Wynn, T., 2019. New Approach to Analysis the Middle Paleolithic Points of the Iranian Plateau: Style vs. Environment. Lithic Technology, 45(1), pp.19-37. https://doi.org/10.1080/01977261.2019.16 86563

Fischer, A., Hansen, P.V. and Rasmussen, P., 1984. Macro and micro wear traces on lithic projectile points: experimental results and prehistoric examples. Journal of Danish archaeology, 3(1), pp.19-46.

Years of Iranian Archeology, by Youssef Hassanzadeh and Sima Miri, Pazineh pp.141-154. pp.388-398. 
1316 Publishing, in collaboration with the 1357

1317 Museum National, Tehran.

1318 Chadelle, J.P., Geneste, J.M. and Plisson, 1360

1319 H., 1986. Le Solutréen de la grotte de 1361

1320 Combe Saunière 1 (Dordogne). Première 1362

1321 approche palethnologique. Gallia 1363

1322 préhistoire, 29(1), pp.9-27.

1323 Giordano, N.J., 2013. College Physics:

1324 Reasoning and Relationships 2nd edn

1325 (Boston, MA: Brooks/Cole Cengage).

1326 Gopher, A., 1994. Arrowheads of the

1327 Neolithic Levant: a seriation analysis (No.

1328 10). Eisenbrauns.

1329 Groucutt, H.S., 2014. Middle Palaeolithic 1372

1330 point technology, with a focus on the site of 1373

1331 Tor Faraj (Jordan, MIS 3). Quaternary 1374

1332 International, 350, pp.205-226.

1333 Hardy, B.L., Moncel, M.H., Daujeard, C., 1376

1334 Fernandes, P., Béarez, P., Desclaux, E., 1377

1335 Navarro, M.G.C., Puaud, S. and Gallotti, 1378

1336 R., 2013. Impossible Neanderthals? 1379

1337 Making string, throwing projectiles and

1338 catching small game during Marine Isotope

1339 Stage 4 (Abri du Maras, France).

1340 Quaternary Science Reviews, 82, pp.23-40.

1341 Hole, F., 1970. The Paleolithic culture 1384

1342 sequence in western Iran. Actes du VII 1385

1343 Congrès de l'UISPP, Bratislava, 1967, 1386

1344 pp.286-293.

1345 Hughes, S.S., 1998. Getting to the point: 1388

1346 evolutionary change in prehistoric 1389

1347 weaponry. Journal of Archaeological 1390

1348 Method and Theory, 5(4), pp.345-408. 1391

1349 https://doi.org/10.1007/BF02428421

1350 Iovita, R., Schönekeß, H., Gaudzinski- 1393

1351 Windheuser, S. and Jäger, F., 2014. 1394

1352 Projectile impact fractures and launching 1395

1353 mechanisms: results of a controlled ballistic 1396

1354 experiment using replica Levallois 1397

1355 points. Journal of Archaeological 1398

1356 Science, 48, pp.73-83.
1375

1392

Javanmardzadeh, A. 2016. Tropical project Report: 20 and 21 grids, Changulee Dam, Transmission System, the Iranian Center for Archaeological. Unpublished (in Farsi). -Lenoir, M., and Villa, P., 2006. Hunting weapons of the Middle Stone Age and the Middle Palaeolithic: spear points from Sibudu, Rose Cottage, and Bouheben. Southern African Humanities, 18(1), pp.89122. https://halshs.archivesouvertes.fr/halshs- 00437400

Kufel-Diakowska, B., Wilczyński, J., Wojtal, P. and Sobczyk, K., 2016. Mammoth hunting-impact traces on backed implements from a mammoth bone accumulation at Kraków Spadzista (southern Poland). Journal of Archaeological Science, 65, pp.122-133.

Mehrpoor Moghadam, M., 2009. Investigation of Throwing Motion of Middle Paleolithic Points, Using the Mousterian Arifacts of Mirak Site, Semnan, Iran (Unpublished dissertation).

Mika, A., Flood, K., Norris, J.D., Wilson, M., Key, A., Buchanan, B., Redmond, B., Pargeter, J., Bebber, M.R. and Eren, M.I., 2020. Miniaturization optimized weapon killing power during the social stress of late pre-contact North America (AD 6001600). Plos one, 15(3), p.e0230348.

Mullen, D., Matney, T., Morrison, A., Fisch, M., Buchanan, B. and Bebber, M.R., 2021. Experimental assessment of NeoAssyrian bronze arrowhead penetration: An initial study comparing bilobate versus trilobate morphologies. Journal of Archaeological Science: Reports, 35, p.102765.

Newman, K. and Moore, M.W., 2013. Ballistically anomalous stone projectile points in Australia. Journal of Archaeological Science, 40(6), pp.26142620.

1400 https://doi.org/10.1016/j.jas.2013.01.023 
1401 Odell, G.H. and Cowan, F., 1986. 1444

1402 Experiments with spears and arrows on 1445

1403 animal targets. Journal of Field

1404 Archaeology, 13(2), pp.195-212.

1405 Oteh, U., 2008. Mechanics of Fluids. 1448

1406 AuthorHouse.

1407 Otte, M., Biglari, F., Flas, D., Shidrang, S.,

1408 Zwyns, N., Mashkour, M., Naderi, R., 145

1409 Mohaseb, A., Hashemi, N., Darvish, J. and 1452

1410 Radu, V., 2007. The Aurignacian in the 1453

1411 Zagros region: new research at Yafteh cave, 1454

1412 Lorestan, Iran. antiquity, 81(311), pp.82-96

1413 Pétillon, J.M., Bignon, O., Bodu, P., Cattelain,

1414 P., Debout, G., Langlais, M., Laroulandie, V.,

1415 Plisson, $H$. and Valentin, B., 2011. Hard core

1416 and cutting edge: experimental manufacture

1417 and use of Magdalenian composite projectile

1418 tips. Journal of Archaeological Science, 38(6),

1419 pp.1266-1283.

1420 Pironneau, O., 1973. On optimum profiles

1421 in Stokes flow. Journal of Fluid

1422 Mechanics, 59(1), pp.117-128.

1423 Plisson, H., 2005. Examen tracéologique

1424 des pointes aziliennes du Bois-Ragot. $L a$

1425 Grotte du Bois-Ragot à Gouex (Vienne).

1426 Magdalénien et Azilien. Société

1427 préhistorique française (Mémoires, 38),

1428 Paris, pp.183-189.

1455 Roustaei, K., 2010. Discovery of Middle

1456 Palaeolithic occupation at high altitude in 1457 the Zagros Mountains, Iran. Antiquity, 1458 84(325).

1459 Salem, P.E. and Churchill, S.E., 2016. 1460 Penetration, tissue damage, and lethality of 1461 wood-versus lithic-tipped projectiles. 1462 In Multidisciplinary approaches to the 1463 study of Stone Age weaponry (pp. 203-212). 1464 Springer, Dordrecht.

1465 Salimipour, S.E., Teymourtash, A.R. and 1466 Mamourian, M., 2018. Performance 1467 Comparison of Several Air Gun Projectiles 1468 with Nose Shape Modification. Modares 1469 Mechanical Engineering, 18(3), pp.3951470405.

1429 Rios-Garaizar, J., 2016. Experimental and 1430 archeological observations of Northern 1431 Iberian Peninsula Middle Paleolithic 1432 Mousterian point assemblages. Testing the 1433 potential use of throwing spears among 1434 Neanderthals. In Multidisciplinary 1435 approaches to the study of Stone Age 1436 weaponry (pp. 213-225). Springer, 1437 Dordrecht. https://doi.org/10.1007/978-
1438 94-017-7602-8_15

1439 Rodriguez-Millan, M., Garcia-Gonzalez,

1471 Sano, K., Arrighi, S., Stani, C., Aureli, D., 1472 Boschin, F., Fiore, I., Spagnolo, V., Ricci, 1473 S., Crezzini, J., Boscato, P. and Gala, M., 1474 2019. The earliest evidence for 1475 mechanically delivered projectile weapons 1476 in Europe. Nature ecology \& 1477 evolution, 3(10), pp.1409-1414.

1478 Sears, W.R., 1947. On projectiles of 1479 minimum wave drag. Quarterly of Applied 1480 Mathematics, 4(4), pp.361-366.

1440 D., Rusinek, A., Abed, F. and Arias, A., 1481 1441 2018. Perforation mechanics of 20241482 1442 aluminium protective plates subjected to 1483 1443 impact by different nose shapes of 1484
Schoville, B.J., Brown, K.S., Harris, J.A. and Wilkins, J., 2016. New experiments and a model-driven approach for interpreting Middle Stone Age lithic point 
1485 function using the edge damage distribution 1527

1486

1487 Shea, J., Davis, Z. and Brown, K., 2001.

1488 Experimental tests of Middle Palaeolithic

1489 spear points using a calibrated crossbow

1490 Journal of Archaeological Science, 28(8),

1491 pp.807-816. Doi:10.1006/jasc.2000.0590.

1492 Shea, J.J. and Sisk, M.L., 2010. Complex

1493 projectile technology and Homo sapiens

1494 dispersal into western Eurasia.

1495 PaleoAnthropology, 2010, pp.100-122.

1496 Doi:10.4207/PA.2010.ART36.

1497 Shea, J.J., 1988. Spear points from the

1498 Middle Paleolithic of the Levant. Journal of

1499 Field Archaeology, 15(4), pp.441-450.

1500 Shea, J.J., 2003. Neandertals, competition,

1501 and the origin of modern human behavior in

1502 the Levant. Evolutionary Anthropology:

1503 Issues, News, and Reviews: Issues, News,

1504 and Reviews, 12(4), pp.173-187.

1505 https://doi.org/10.1002/evan.10101.

1506 Shea, J.J., 2006. The origins of lithic

1507 projectile point technology: evidence from

1508 Africa, the Levant, and Europe. Journal of

1509 Archaeological Science, 33(6), pp.823-846.

1510 Doi: 10.1016/j.jas.2005.10.015

1511 Shea, J.J., 2013. Stone tools in the

1512 Paleolithic and Neolithic Near East: a

1513 guide. Cambridge University Press.

1514 Shea, J.J., Brown, K.S. and Davis, Z.J., 1557

1515 2002. Controlled experiments with Middle 1558

1516 Palaeolithic spear points: Levallois points. 1559

1517 Experimental archaeology: replicating 15608

1518 past objects, behaviors, and processes,

1519 1035, pp.55-72.

1520 Sisk, M.L. and Shea, J.J., 2009. 1563 2017. The first evidence for Late

1521 Experimental use and quantitative 1564 Pleistocene hominin populations on the

1522 performance analysis of triangular flakes 1565

1523 (Levallois points) used as arrowheads. 1566

1524 Journal of Archaeological Science, 36(9), 1567

1525 pp.2039-2047.

1526 10.1016/j.jas.2009.05.023 a 1555

1556

1561 Vahdati Nasab, H., Roustaei, K., Fatideh,

1562 M.G., Shojaeefar, F. and Sarvandi, M.H.,

Sisk, M.L. and Shea, J.J., 2011. The African origin of complex projectile technology: an analysis using tip cross-sectional area and perimeter. International Journal of Evolutionary Biology, 2011. Doi: 10.4061/2011/968012.

Sitton, J., Story, B., Buchanan, B. and Eren, M.I., 2020. Tip cross-sectional geometry predicts the penetration depth of stonetipped projectiles. Scientific Reports, 10(1), pp.1-9.

Sperrazza, J. and Kokinakis, W., 1968. Ballistic limits of tissue and clothing. Annals of the New York Academy of Sciences, 152(1), pp.163-167.

Thomas, D.H., 1978. Arrowheads and atlatl darts: how the stones got the shaft. American Antiquity, 43(3), pp.461-472. DOI: $10.2307 / 279405$.

Vahdati Nasab, H., 2010. Paleolithic archaeology in Iran. Intl. $J, 18$, p.1. https://www.researchgate.net/publication/2 88263080_Paleolithic_archaeology_in_Ira n.

Vahdati Nasab, H., Clark, G.A., and Torkamandi, S., 2013. Late Pleistocene dispersal corridors across the Iranian Plateau: a case study from Mirak, a Middle Paleolithic site on the northern edge of the Iranian Central Desert (Dasht-e Kavir). Quaternary International, 300, pp.267281.

https://doi.org/10.1016/j.quaint.2012.11.02 southern Caspian Sea coast. Antiquity, 91(355).

https://doi.org/10.15184/aqy.2016.232

Doi: 1568 Vahdati, Nasab, H., and Hashemi, M., 1569 2016. Playas and Middle Paleolithic 
1570 settlement of the Iranian Central Desert: the 1593

1571 discovery of the Chah-e Jam Middle 1594

1572 Paleolithic site. Quaternary International, 1595

1573 408, pp.140-152.

1574 Villa, P. and Soriano, S., 2010. Hunting

1575 weapons of Neanderthals and early modern 1598

1576 humans in South Africa: similarities and 1599

1577 differences. Journal of Anthropological 1600

1578 Research, 66(1), pp.5-38.

1579 Vogel, S., 2005. Living in a physical world

1580 V. Maintaining temperature. Journal of

1581 Biosciences, 30(5), pp.581-590.

1582 https://doi.org/10.1007/BF02703556

1583 Vogel, S., 1994. Life in moving fluids: the

1584 physical biology of flow. Princeton

1585 University Press.

1586 Von Kármán, T., 1963. Aerodynamics (Vol.

1587 9). New York: McGraw-Hill.

1588 Wilkins, J., Schoville, B.J., Brown, K.S.

1589 and Chazan, M., 2012. Evidence for early 1612

1590 hafted

1591 technology. Science, 338(6109), pp.942-

1592946.
1596

Wilkins, J., Schoville, B.J. and Brown, K.S., 2014. An experimental investigation of the functional hypothesis and evolutionary advantage of stone-tipped spears. PloS one, 9(8), p.e1045

Wilkins, J. and Chazan, M., 2012. Blade production 500 thousand years ago at Kathu Pan 1, South Africa: support for a 1601 multiple origins hypothesis for early 1602 Middle Pleistocene blade technologies. 1603 Journal of Archaeological Science, 39(6), 1604 pp.1883-1900.

1605 Wilson, J.D. and Buffa, A.J., 2000. College 1606 Physics: Student Study Guide and Solutions 1607 Manual. Prentice Hall.

1608 Wingrove, A.L., 1973. The influence of 1609 projectile geometry on adiabatic shear and 1610 target failure. Metallurgical 1611 Transactions, 4(8), pp.1829-1833.

1614 Appendix

\begin{tabular}{lccc}
\hline \multicolumn{1}{c}{$\begin{array}{c}\text { retouched Mirak } \\
\text { points }\end{array}$} & n & Mean & S.d \\
\hline Weight (g) & 143 & 12.7 & 7.6 \\
\hline Area & 143 & 1253 & 468.5 \\
\hline Length (mm) & 143 & 51.9 & 10.7 \\
\hline Width at med (mm) & 143 & 24.7 & 6.4 \\
\hline Max width (mm) & 143 & 28.4 & 8.1 \\
\hline Thickness at med (mm) & 143 & 7.5 & 2.5 \\
\hline Max thickness (mm) & 143 & 9.2 & 4.5 \\
\hline Volume (mm3) & 143 & 14134 & 8422.5 \\
\hline Elongation & 143 & 1.99 & 0.8575 \\
\hline Flattening & 143 & 3.4 & 1.04 \\
\hline Platform flattening & 143 & 3.4 & 1.4 \\
\hline $\begin{array}{l}\text { Relative platform } \\
\text { size(mm3) }\end{array}$ & 143 & 185.1 & 118.9 \\
\hline $\begin{array}{l}\text { TCSA } \\
\text { retouched in Chah-e- } \\
\text { jam points }\end{array}$ & $\mathrm{n}$ & Mean & S.d \\
\hline
\end{tabular}




\begin{tabular}{|c|c|c|c|}
\hline Weight (g) & 57 & 11.9 & 7.2 \\
\hline Area & 57 & 1055.4 & 481.3 \\
\hline Length (mm) & 57 & 42.6 & 10.4 \\
\hline Width at med (mm) & 57 & 24.6 & 5.5 \\
\hline Max width (mm) & 57 & 28.2 & 6.6 \\
\hline Thickness at med (mm) & 57 & 7.6 & 2.3 \\
\hline Max thickness (mm) & 57 & 9.13 & 4.3 \\
\hline Volume (mm3) & 57 & 12261.9 & 8500.5 \\
\hline Elongation & 57 & 1.5 & 0.3 \\
\hline Flattening & 57 & 3.3 & 0.9 \\
\hline Platform flattening & 57 & 3.4 & 1.2 \\
\hline $\begin{array}{l}\text { Relative platform } \\
\text { size(mm3) }\end{array}$ & 57 & 196.5 & 110 \\
\hline TCSA & 57 & 133.5 & 62.3 \\
\hline $\begin{array}{l}\text { Retouched } \\
\text { Khuhrangh points }\end{array}$ & $\mathrm{n}$ & Mean & S.d \\
\hline Weight (g) & 22 & 21.1 & 10.5 \\
\hline Area & 22 & 1719.3 & 518.3 \\
\hline Length (mm) & 22 & 57.9 & 9.12 \\
\hline Width at med (mm) & 22 & 28.4 & 5.04 \\
\hline Max width (mm) & 22 & 28.3 & 8.04 \\
\hline $\begin{array}{l}\text { Retouched } \\
\text { Khuhrangh points }\end{array}$ & $\mathrm{n}$ & Mean & S.d \\
\hline Thickness at med (mm) & 22 & 10.9 & 3.06 \\
\hline Max thickness (mm) & 22 & 15.6 & 9.6 \\
\hline Volume (mm3) & 22 & 23221.1 & 10759.7 \\
\hline Elongation & 22 & 2.3 & 0.9 \\
\hline Flattening & 22 & 2.3 & 1.1 \\
\hline Platform flattening & 22 & 2.7 & 0.9 \\
\hline $\begin{array}{l}\text { Relative platform } \\
\text { size(mm3) }\end{array}$ & 22 & 268.8 & 119.9 \\
\hline TCSA & 22 & 195.9 & 65.09 \\
\hline $\begin{array}{l}\text { Retouched Bandepey } \\
\text { points }\end{array}$ & $\mathrm{n}$ & Mean & S.d \\
\hline Weight (g) & 27 & 26.7 & 21.6 \\
\hline Area & 27 & 2060.3 & 989.6 \\
\hline Length (mm) & 27 & 59.6 & 15.6 \\
\hline Width at med (mm) & 27 & 31.9 & 9.4 \\
\hline Max width (mm) & 27 & 37.5 & 10.7 \\
\hline
\end{tabular}




\begin{tabular}{|c|c|c|c|}
\hline Thickness at med (mm) & 27 & 10.7 & 3.9 \\
\hline Max thickness (mm) & 27 & 12.9 & 3.7 \\
\hline Volume (mm3) & 27 & 33422.2 & 30027.2 \\
\hline Elongation & 27 & 1.63 & 0.32 \\
\hline Flattening & 27 & 2.9 & 0.74 \\
\hline Platform flattening & 27 & 3.02 & 1.2 \\
\hline $\begin{array}{l}\text { Relative platform } \\
\text { size }(\mathrm{mm} 3)\end{array}$ & 27 & 360.4 & 223.6 \\
\hline TCSA & 27 & 252.2 & 133.1 \\
\hline $\begin{array}{l}\text { Retouched Mehran } \\
\text { points }\end{array}$ & $\mathrm{n}$ & Mean & S.d \\
\hline Weight (g) & 31 & 13.9 & 10.5 \\
\hline Area & 31 & 1235.3 & 604.7 \\
\hline Length (mm) & 31 & 46.3 & 12.04 \\
\hline Width at med (mm) & 31 & 23.4 & 7.2 \\
\hline Max width (mm) & 31 & 27.08 & 7.8 \\
\hline Thickness at med (mm) & 31 & 9.9 & 5.4 \\
\hline Max thickness (mm) & 31 & 10.25 & 3.3 \\
\hline Volume (mm3) & 31 & 15286.1 & 11351.1 \\
\hline Elongation & 31 & 1.8 & 0.38 \\
\hline Flattening & 31 & 2.7 & 0.7 \\
\hline $\begin{array}{l}\text { Retouched Mehran } \\
\text { points }\end{array}$ & $\mathrm{n}$ & Mean & S.d \\
\hline Platform flattening & 31 & 2.5 & 0.92 \\
\hline $\begin{array}{l}\text { Relative platform } \\
\text { size }(\mathrm{mm} 3)\end{array}$ & 31 & 180.4 & 121.1 \\
\hline TCSA & 31 & 148.3 & 80.1 \\
\hline Unretouched points & $\mathrm{n}$ & Mean & S.d \\
\hline Weight $(\mathrm{g})$ & 6 & 10.1 & 7.8 \\
\hline Area & 6 & 1013.8 & 474.6 \\
\hline Length (mm) & 6 & 42.4 & 7 \\
\hline Width at med (mm) & 6 & 23.5 & 7 \\
\hline Max width (mm) & 6 & 24.5 & 8 \\
\hline Thickness at med (mm) & 6 & 8.2 & 2.9 \\
\hline Max thickness (mm) & 6 & 13.3 & 12.7 \\
\hline Volume (mm3) & 6 & 12747.9 & 9453.2 \\
\hline Elongation & 6 & 1.9 & 0.9 \\
\hline Flattening & 6 & 2.8 & 1.2 \\
\hline Platform flattening & 6 & 3.4 & 0.98 \\
\hline
\end{tabular}




\begin{tabular}{lccc}
\hline $\begin{array}{l}\text { Relative platform } \\
\text { size }(\mathrm{mm} 3)\end{array}$ & 6 & 149.3 & 56.1 \\
\hline TCSA & 6 & 140.5 & 82.4 \\
\hline
\end{tabular}

Table 1. Descriptive statistics for Levallois point morphology on sites inside Iran.

\begin{tabular}{cccc}
\hline retouched Tor Faraj points & n & Mean & S.d \\
\hline Weight $(\mathrm{g})$ & 107 & 14.4 & 8.5 \\
\hline Length (mm) & 107 & 54.9 & 13.4 \\
\hline Width at med (mm) & 107 & 28.2 & 7.4 \\
\hline Max width (mm) & 107 & 37 & 9.8 \\
\hline Thickness at med (mm) & 107 & 7.9 & 2.3 \\
\hline Max thickness (mm) & 107 & 7.9 & 2.3 \\
\hline Volume (mm3) & 107 & 10788.4 & 7123.5 \\
\hline Elongation & & & \\
\hline Flattening & 107 & 2.0 & 0.6 \\
\hline Platform flattening & 107 & 4.7 & 1.2 \\
\hline Relative platform size(mm3) & 107 & 6.1 & 2.1 \\
\hline TCSA & 107 & 8.9 & 5.9 \\
\hline
\end{tabular}

\begin{tabular}{|c|c|c|c|}
\hline Unretouched points & & & \\
\hline Weight (g) & 90 & 13.8 & 8.4 \\
\hline Length $(\mathrm{mm})$ & 90 & 53.9 & 13.4 \\
\hline Width at med (mm) & 90 & 28.0 & 7.2 \\
\hline retouched Tor Faraj points & n & Mean & S.d \\
\hline Max width (mm) & 90 & 36.9 & 9.7 \\
\hline Thickness at med (mm) & 90 & 6.1 & 1.9 \\
\hline Max thickness (mm) & 90 & 7.7 & 2.3 \\
\hline Volume (mm3) & 90 & 10381.0 & 6699.7 \\
\hline Flattening & 90 & 4.8 & 1.1 \\
\hline Elongation & 90 & 2.0 & 0.5 \\
\hline Platform flattening & 90 & 6.1 & 2.1 \\
\hline Relative platform size $(\mathrm{mm} 3)$ & 90 & 8.7 & 0.5 \\
\hline TCSA & 90 & 149.5 & 72.2 \\
\hline \multicolumn{4}{|l|}{ Retouched points } \\
\hline Weight $(\mathrm{g})$ & 17 & 17.7 & 11.0 \\
\hline Length $(\mathrm{mm})$ & 17 & 60.5 & 12.3 \\
\hline Width at med (mm) & 17 & 29.1 & 8.3 \\
\hline
\end{tabular}




\begin{tabular}{cccc}
\hline Max width (mm) & 17 & 38.8 & 10.2 \\
\hline Thickness at med (mm) & 17 & 6.7 & 2 \\
\hline Max thickness (mm) & 17 & 8.6 & 2.1 \\
\hline Volume (mm3) & 17 & 12945.4 & 8979.3 \\
\hline Flattening & 17 & 4.5 & 1.4 \\
\hline Elongation & 17 & 2.2 & 0.8 \\
\hline Platform flattening & 17 & 6.2 & 2.1 \\
\hline Relative platform size (mm3) & 17 & 8.1 & 3.8 \\
\hline TCSA & 17 & 174.1 & 76.4 \\
\hline
\end{tabular}

1618

1619

Table 2. Descriptive statistics for Levallois point morphology in Tor Faraj points (Groucutt, 2014). 